\title{
Validity and Rigour in Soma Design-Sketching with the Soma
}

\author{
ANNA STÅHL, Research Institutes of Sweden \\ VASILIKI TSAKNAKI, IT University of Copenhagen \\ MADELINE BALAAM, KTH Royal Institute of Technology
}

We report on the design processes of two ongoing soma design projects: the Pelvic Chair and the Breathing Wings. These projects take a first-person, soma design approach, grounded in a holistic perspective of the mind and body (the soma). We contribute a reflective account of our soma design processes that deepens the field's understanding of how soma design is achieved through first-person approaches. We show how we use our somas, our first-person experiences, to stimulate a design process, to prototype through and to use as a way of critiquing emerging designs. Grounding our analysis in new materialism, we show how our designs are in essence, "performative intra-actions". Using our own somas, our designs open up for experiences within certain constraints, allowing for a material-discursive agency of sorts. Many different somas may be intraacted through our designs, even if it was our somas who started them.

\section{CCS Concepts: • Human-centered computing $\rightarrow$ Interaction design process and methods;}

Additional Key Words and Phrases: Soma design, feminism, first-person perspectives, new materialism, design critique, design methods, sketching

\section{ACM Reference format:}

Anna Ståhl, Vasiliki Tsaknaki, and Madeline Balaam. 2021. Validity and Rigour in Soma Design-Sketching with the Soma. ACM Trans. Comput.-Hum. Interact. 28, 6, Article 38 (December 2021), 36 pages.

https://doi.org/10.1145/3470132

\section{INTRODUCTION}

Soma design [37] is an approach to designing novel interactive experiences with the body. Soma design takes a holistic perspective of the mind and body-the soma-as a starting point in design processes, and is characterised by using the designer's soma and their first-person experiences and reflections as a guide to judge, validate, and iterate throughout a design process. Accounts of how soma design methods use first-person experiences have been previously articulated in $[37,38,44,65,70]$. What these previous accounts successfully highlight is that first-person perspectives are fundamental for soma design: One needs to understand first connections between sensations, emotions, and felt somatic experiences with digital and physical materials, through experiencing them themselves, before aiming to design such connections for others. However, they

\footnotetext{
We acknowledge funding from VR, and SSF, who have made this work possible.

Authors' addresses: A. Ståhl, Research Institutes of Sweden, Box 1263, 16429 Kista; email: Sweden, anna.stahl@ri.se; V. Tsaknaki, IT University of Copenhagen, Rued Langgaards Vej 7, 2300 København, Denmarkxa; email: vats@itu.dk; M. Balaam, KTH Royal Institute of Technology, Lindstedsvägen 5, 11428 Stockholm, Sweden; email: balaam@kth.se.

Permission to make digital or hard copies of all or part of this work for personal or classroom use is granted without fee provided that copies are not made or distributed for profit or commercial advantage and that copies bear this notice and the full citation on the first page. Copyrights for components of this work owned by others than ACM must be honored. Abstracting with credit is permitted. To copy otherwise, or republish, to post on servers or to redistribute to lists, requires prior specific permission and/or a fee. Request permissions from permissions@acm.org.

(C) 2021 Association for Computing Machinery.

1073-0516/2021/12-ART38 \$15.00

https://doi.org/10.1145/3470132
} 

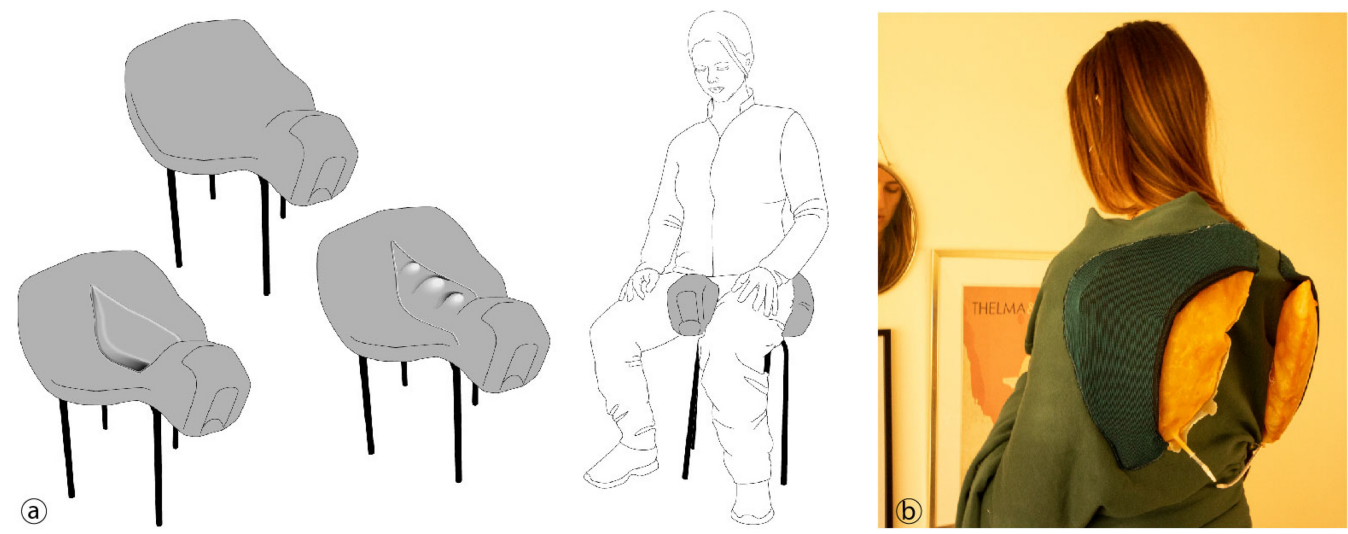

Fig. 1. The two prototypes were developed through soma design methods: (a) The Pelvic Chair aims at raising pelvic floor awareness, by making use of soft shape-changing technology, and (b) the Breathing Wings invites the wearer to a dynamic embracing experience on the shoulder blades, through soft shapechanging technology.

lack a detailed presentation of how first-person methods unfold when designing with somas. In addition, existing literature does not provide details on how to make design judgements through using one's first-person somatic experiences from the perspective of a designer, nor how to ensure rigour in this first-person focused design process.

In this article, we respond to this gap by presenting and elaborating on how we have taken the first-person approach in developing two ongoing soma design projects: the Pelvic Chair and the Breathing Wings (Figure 1). The Pelvic Chair aims at raising pelvic floor awareness, by making use of soft shape-changing technology. When it is sat upon, parts of the seat of the chair move-to encourage the user to sit upright, to open their legs slightly, and then to "touch" different parts of the pelvic floor muscles, so as, to help to feel and develop awareness of these muscles. In contrast, the Breathing Wings are worn on the back and torso. Through a dynamic embracing experience, also created through soft shape-changing technology, the wearable allows the wearer to remember and re-experience neglected body parts, the shoulder blades, where it evokes different qualities of "touch". By putting these two projects in dialogue with one another, and through presenting an analysis of how first-person methods were used in each design process, we offer two contributions.

We first contribute a detailed account of how first-person experiences drive forward a design process by enabling a deep, careful, and devoted approach to interaction design, which unravels the full potential of technological materials and somas for a particular design context. We show how we use our somas and our first-person experiences to stimulate each design process. We illustrate how we prototype through our somas, and use our somas as a way to critique design. The combination of the two projects enables us to articulate four key anchor points, which we offer as concrete practical and reflective paths for other practitioners to use as guidance when engaging in first-person perspectives in design work, which have their soma as a starting point. By presenting a series of rich descriptions of our soma design processes, we intend to vividly illustrate how soma design happens with rigour. We show how a red thread is developed and nurtured through firstperson methods, that runs from the establishment and iterative return to somatic design qualities, through an engagement with materials and the soma to evoke those experiential design qualities in interactions (Figure 2). By following this red thread, we articulate a design process that has purpose, momentum, and logic.

Our second contribution aims at tackling a significant omnipresent query with regards to firstperson methods in soma design, that of how such an approach can contribute to the creation 
of artefacts that have meaning for others. First-person methods challenge notions of validity in Human-Computer Interaction (HCI) by using the primacy of the self as a mode for generating knowledge, designs, and understanding other somas. HCI and interaction design historical roots are in engineering, computing science, and psychology. Empirical, quantitative studies of design and technology in use have been our field's bread and butter position on knowledge-making for many years. And, from this, we have as a field created an epistemological position that places great emphasis on rigour and validity on knowledge generated through varying forms of objective studies of users (whether in the lab, design workshop, or in the field) [54]. It is therefore no wonder that there is great scepticism and debate as to whether design and studies, which centre on the subjective designer/researchers' experiences can be seen as an equally valid and rigorous approach to knowledge making [7, 54, 73]. From Bill Gaver's Cultural Probes[26] and Jayne Wallace's Design Probes [68], to an increasing presence of research through design in HCI and Interaction Design research, the tides of what constitutes knowledge in our field are changing. Yet, first-person methods and their use in Soma Design continue to cause trouble in terms of what can be constituted knowledge in interaction design research [66]. How can something as subjective as first-person methods and one unique soma respond to develop a design prototype intended to be used by others? This approach will not simply result in narcissistic research prototypes that have little value or meaning to others? How can you be sure that the design does not only speak to your particular somatic experiences and no one else's?

In this article, we seek to respond to these questions. We illustrate that first-person experiences can indeed provide validity through explicitly designing for a plurality in experience. Jeffrey Bardzell and colleagues write that in research knowledge is transmitted verbally, but in RtD it (knowledge) is embodied in the object [7]. We take this one step further, and through the application of a new materialism perspective [4] illustrate that in soma design, (design and somatic) knowledge is developed in the intra-action between the soma and the materials (emerging design). From our perspective, soma design results in designs that are in themselves "performative intra-actions": designed experiences that remain "open" for a plurality of bodies to "complete" or "fill" with their own meaning. In turn, this meaning produces new knowledge, that is, creates new worlds-it becomes world making for the soma experiencing it [5]. It is our aspiration that many different somas may create meaning through intra-actions with our designs, even if it was our somas who started them. In this sense, we also draw from ongoing discourse in feminist research which advocates for "applicability" as an alternative lens on "validity" in research and knowledge making [14].

\section{BACKGROUND}

\subsection{First-Person Methods in Design and HCI}

First-person methods are being utilised in a number of different ways throughout HCI and Interaction Design research and practice. First-person perspectives have been classified into two main categories: autoethnographic, and autobiographical design including autobiographical research through design [51]. The first-person approach to research has not been commonplace within HCI and Interaction Design. In 2006 Bill Gaver [27] published work, describing his personal explorations of creating a "video window", which he lived within his own home for over six months. Bill Gaver, draws on his and his family's first-person experiences of the system to discuss the utility of such a set-up, and to highlight how it provides a rich, meaningful and ludic experience, even though very simple technologies are applied. While not explicitly calling his approach as autobiographical or autoethnographic, it served to sow the seeds of acceptability of the first-person experience as a way of developing applicable knowledge within the field. In the following section, we provide a brief overview of autoethnographic, and autobiographical approaches to HCI and Interaction Design research, and approaches to knowledge contribution that these utilise. 
2.1.1 Autoethnographic Approaches in HCl. Autoethnographic work has generally been utilised within the field as a mode of "evaluation" through, which researchers attempt to understand the phenomenological, or post-phenomenological experiences of a finalised commercial or prototype technology, or processes associated with designing a technology. Aisling O'Kane explicitly utilises an autoethnographic method to better understand, gain first-hand experience of, and develop empathy for individuals who use mobile medical devices to manage medical conditions [55]. Based on an autoethnographic study conducted over three months, the researchers argue that autoethnography is a useful additional tool for researchers to understand the use of a designed product, particularly in non-routine situations. Beyond this, they argue that by ensuring the researcher remains aware of the subjectivity of their dataset, the collected data can still produce useful research insights for the field of HCI, although they also highlight that this data should not be viewed as more important than traditional usability studies. More recently, Marta Cecchinato [10] combined a user study with an autoethnography to closely analyse the user experience of the then new-to-the market smart watch. In this case, the autoethnographic account is used both to develop the interview questions with other users, and thus shapes the direction of the research (or what is interesting), while also adding where necessary additional nuance to the accounts of user experience provided in the article. Andrés Lucero [50] published an autoethnographic account of his experiences of living without a mobile phone over nine years. Within this work, he purposes resisting generating a set of design guidelines based on his experiences, and instead uses his analysis to show how his reflections may be relevant to those who are involuntarily disconnected due to a variety of circumstances. Andrés Lucero attends to how he and the reader may think about the validity and rigour of the published account, presenting study boundaries, authenticity, plausibility, criticality, self-revealing writing, interlacing ethnographic material with confessional content, and generalisability as a series of pillars by which his, and other autoethnographic work may be judged. In a similar vein, Sarah Homewood and colleagues use autoethnographic accounts to describe the effects of living without self-tracking technologies [33]. Similarly to [10], the authors integrate their autoethnographic reflections alongside interview data within their analysis in order to examine the emotional, embodied and cultural knowledge and entanglements that self tracking applications produce, and this method reveals. Finally, in [3] Madeline Balaam and her colleagues describe and discuss their first-person, emotion work experiences of undertaking experience-centred design across multiple design contexts. Making use of a story-based approach, the researchers' quote [20] to discuss how their stories should be considered useful if ...it raises questions and engenders passionate conversation, encouraging readers to connect the events and experiences of the characters in the story to their own lives [20]. Similar to the generalisability and criticality criteria asserted in [50], a prime way of understanding the knowledge contribution of autoethnographic research is the extent to which it resonates with, and moves the reader to think or act differently. In this sense, it is the reader who determines the validity and usefulness of the research within the context of their own lives and experiences.

2.1.2 Autobiographical Design and Research through Design. Autobiographical design and autobiographical research through design, focus more squarely on using the experiences of the self as an explicit action within the design process. Carman Neustaedter and Phoebe Sengers introduce autobiographical design as a way of developing systematic understandings of a system's potential [54]. They highlight that designers, developers and engineers using and testing their own systems throughout a design process is common practice, and enables the developer to understand the bugs in their thinking and system before releasing the design for wider use. However, based on a series of interviews with (mostly male) individuals who utilise autobiographical design, the authors argue that autobiographical design should be seen as something deeper than solely testing and 
refining design. Instead, it is better understood as a developer designing and building something for themselves (based on their own needs/interests), and then using, testing, and refining the design in order to understand the design space, as well as improve the design. In these earlier empirical explorations of how designers, developers and engineers practice autobiographical design in their own work, the "taboo" nature of this approach to research becomes clear. Interviewees report limiting the extent to which they describe their own autobiographical design within formal project publications (for fear of rejection by peers), as well as experiencing tensions in publishing their own autobiographical design work. Somewhat similar in approach, Xiao Zhang and Ron Wakkary [73] use interviews with professional designers to explore how personal experiences influence interaction design practice. Their work corroborates Carman Neustaedter's earlier reports that designers tend to obfuscate how their personal experiences may influence their design judgements since this conflicts with the user-centred, and rational approach that populates design rhetoric.

Autobiographical design has begun to find its value for the field, as one method for studying complex, long-term, personal situations with design/technology. Audrey Desjardins and Aubree Ball emphasise in their reflection of use of autobiographical design how the methodological innovation in autobiographical design supports situated, intimate, and long-term research, which would be challenging to undertake using alternative methods [15]. Yasamin Heshmat et al. [32] report on a long-term deployment of an always-on video camera system with the intention of supporting memory making/recording. This is a good example of such a project, which would be very difficult to achieve using third-person methods. In this instance, the authors [32] utilise autobiographical design to explore an emerging design space. An always-on, recording device, deployed over the long-term within a family home, is many researchers' idea of an ethics and logistics nightmare in the making. By, using the alternative method of autobiographical design, and principally using the technology within the researcher's family home, the authors are able to explore the meaning and use of such a set-up over the long-term with a family who are motivated to use the technology in ways, which help them articulate the design space.

Audrey Desjardins and Aubree Ball [15] call for researchers to show more of their design practices, to show how materials are explored and decisions are made in order to support designers within the field in developing our craft. Correspondingly, more published work is emerging, which not only presents researchers' autobiographical experiences of living with systems, but also a more open first-person centred description of how the designers' experiences are accounted for within design work, as part of a research through design practice. In [16], Audrey Desjardins and Ron Wakkary describe the 23-month project of converting a van into a camper van. The authors make use of first-person, autobiographical research through design process to offer a rich and detailed personal reflection on maker/user practices within purpose-built environments. Here, again, the designers emphasise that autobiographical design fulfils a genuine need (of the designer), is used over a long period of time, and that the designer is the user of the system. What is particularly interesting are the reflective accounts of their design work. The authors highlight the various ways their bodies, their intimate knowledge of themselves, and increasingly the van changed their perceptions of what the van is, could be, and how it should be treated. Perhaps because of the nature of autobiographical research through design, we also begin to see design researchers using this technique in order to tackle difficult and intimate subject matters. Refind [67], for example, shows Jayne Wallace and her team's exploration of how digital technologies may engage with with experiences of ongoingness and bereavement. Through first-person explorations within a research through design process, the authors show how what feels natural to them as they tinker with early prototypes can be drawn through into how interactions are rendered in their final, and rather beautiful research artifact. The authors discuss how the use of autobiographical methods move beyond the pragmatics of being able to do design work on a complex and sensitive subject, to enabling a 
research through design approach, where the authors can through living with the prototype, more fully understand the concept of ongoingness, how it is embodied within the device, and the theoretical positions they were seeking to build. Another alternative perspective on autobiographical design in research through design can be found in Laura Devendorf and co-authors' design memoirs. Making design memoirs uses designed objects as first-person, embodied reflections, with the intention of providing a different way to tell about intimate, personal experiences [19], and thus to inspire new ways to approach design space. The authors/designers, thus offer their own personal design memoirs as a way of telling a different kind of story about motherhood, and one which works against the norms of motherhood presented in everyday media and technology [18]. Much in line with previous discourse on the role of the personal in design, the authors encourage designers to recognise how their personal experiences shape their design practice, and vice versa. In contrast to autobiographical design, as it has previously been formulated, the intention behind these objects is not to facilitate a form of long-term, situated use, nor to tightly knit together a make/use loop, but instead to resonate with others on an emotional, sensual and subjective level.

2.1.3 What Kind of Knowledge is Being Produced? Much of the research discussed above explicitly states that it does not aim at producing generalisable findings, but has other aims which are equally useful and valid for our community-from providing stories and objects to think with $[3,19]$, to enriching our understanding of how technologies might be used and embedded within our lives $[33,50]$, to enabling us to better understand the future possibilities of interactions with the digital within intimate spaces [72], [16]. And, in [16], [19], and [67], the authors start to share the particulars of how their personal experiences, bodies, and emotions, are captured within the design work that they produce. These all seek to inform our community of aspects of technology use and experience that many of us are interested in, while offering insights into new possible directions for design and research. This contrasts slightly with soma design practices, which similarly use first-person methods to inform and drive a design process, but where the intention is very much to design an artefact, which does generalise (in a way) to use by other somas [37].

\subsection{Soma Design}

Soma Design is a method of doing design work that has caught the interest of researchers in the HCI community lately $[9,52,65]$. Soma design has been developed and is currently applied as a method that suggests concrete ways of addressing and actively engaging the soma, in designing interactions-both the designer's and the end-user's somas [37]. It has its roots in the philosophy of somaesthetics, which is an interdisciplinary field developed by the philosopher Richard Shusterman [60], and grounded in pragmatist philosophy and phenomenology. Richard Shusterman [60] defines somaesthetics as the critical study and meliorative cultivation of the soma as a site both of sensory appreciation (aesthesis) and creative self-fashioning (p.111). Soma design in HCI draws on this philosophy that combines the word soma (i.e., the body as a whole including the fleshy body, mind, emotions, subjective understandings, and values) with aesthetics, as the sensory appreciation and cultivation of our somas. In order to understand, how soma design is positioned in relation to more "traditional" theories of embodiment and embodied interaction in HCI, the key is to take into account the moving and living body, as described by the philosopher and dancer Maxine Sheets-Johnstone [59]. According to her [59], when working with the body (in any practice including dance or design), we cannot simply add an "embodied view" on it. But instead, we need to incorporate the actual living, corporeal body with its muscles and moving limbs into our ways of approaching bodies as part of physical, social and temporal spaces, capable of shaping experiences. Therefore, the importance of movement and of becoming attentive to our fleshy bodies can hardly be overestimated, not only in our lives more broadly, but also in the area of design. 
There is a variety of strategies used when doing soma design that aim at opening up the design space with a strong focus on the designer's soma for improving somaesthetic awareness, and have as an ultimate goal to design rich experiences with technologies for end-users [37]. Developing somatic knowledge is a new and essential type of a design skill. In order to train the somatic knowledge, the designer needs to incorporate movement as part of a design process, and switch to sketching through the movements instead of using pen and paper [34]. One proposed strategy is to engage with bodily activities such as yoga, dance, or any other, pertaining to a particular design context, and repeat such activities over time. In that way, one can become attentive to their bodies through first-person somatic experiences and reflections, before designing somatic and interactive experiences for others.

Sarah Fdili Alaoui and colleagues [21] provide a close examination of the processes and practices by which three leading interaction designers in the area of soma design access and bring the qualities and experiences of their somas into a design process. They identify several challenges to these processes and practices, including being able to stay engaged with inner somatic experiences, being able to articulate these experiences through language, and to others (collaborators, participants, readers). Fittingly, workshops at $\mathrm{CHI}[34,35]$ also aimed at exploring and deepening the method space for designing somaesthetic interactions and increasing somatic mastery of HCI practitioners. Since, interaction designers are often not skilled in designing using their soma including movement, emotion, and holistic engagements, Thecla Schiphorst [57] suggests engaging with Somatic Connoisseurs (e.g., choreographers, yoga instructors, culinary chefs) to support the design team. In addition to working with connoisseurs, several researchers in HCI working with the soma adopted techniques inspired by Feldenkrais, theatre, dance, or other somatic or artistic practices. Among others, Dag Svanaes et al. have collaborated with theatre [63], Lian Loke et al. have engaged with dancers [47], and George Khut et al. [43] have engaged with the arts. Two somatic practices, we have turned to in our design processes are Feldenkrais [22] and Contact Improvisation. The first one is about performing habitual movements extremely slow aiming to de-contruct, and intimately extend the repertoire of our movements through re-learning to do mundane movements in slightly different ways. The second, Contact Improvisation, is a form of improvised dancing focusing on exploring one's body in relationship to others by using the fundamentals of sharing weight, touch, and movement awareness.

Another strategy that is common in soma design is to work with estrangement [69] and defamiliarisation [48] as a way of introducing change and maintaining interest [41]. The concept of estrangement describes the act of experiencing something that occurs in the moment of perception and that the further you confuse or otherwise prolong the moment of arriving at an understanding, the deeper or more detailed that understanding will be [69]. Subdividing experiences (e.g., bodily or emotional) to smaller aspects and then engaging in activities that shift focus from one aspect of an experience to another and back, can be one path to providing a more nuanced and rich understanding of an experience [37]. This can be done for example, by slowing down a movement in order to observe it, as in the case of doing Feldenkrais exercises, or by making "strange" through disrupting the habitual ways we engage in a movement or with one another. What these strategies suggest is to destabilise habit by "making the familiar strange" aiming to open up a design space.

First-person perspectives are commonly used in soma design since the designer's soma is usually the starting point of delving deep into a design space and of exploring digital and physical materials. As articulated in [37], the materials being shaped in a soma design process are not only the digital and physical materials used to build an interactive artifact with, but also the designers' and the end users' somas, as their interactions with the system/artifact will change and affect their experiences of sensual appreciation and movement. This means that articulations of first-person experiences arising through our somas, as designers, are in a sense a design material that needs to be explored 
and worked with [70]. In a soma design process, our bodies and our subjective experiences, feelings, values, meaning-making, and movement-based engagements are altered by the design process, and the living body becomes a resource for design. However, even if soma design makes use of firstperson methods (as acknowledged for example in [38]), and has always done, the details of how the design process unfolds through first-person engagements, and how learnings from such a process affect design judgements throughout the design process, lack a detailed description. For example, as noted by Vasiliki Tsaknaki et al. [66], it is hard to teach soma design to postgraduate students, but also to designers who are new to soma design methods, more broadly. This is due to the fact that there is a lack of detailed accounts on how to use one's first-person experiences and bodies as a way to critique steps of a design process and to take active design decisions along the way. In this article, we respond to this gap by offering a detailed account of doing soma design in two ongoing projects, and through that, we are tracing core design phases along the way, where design judgements are made.

\section{TWO ONGOING SOMA DESIGN PROJECTS: THE PELVIC CHAIR AND THE BREATHING WINGS}

The design processes for the Pelvic Chair and the Breathing Wings began separately. In the two first points (see Figure 2) that will be described in more detail below, Anna and Madeline were working together on the Pelvic Chair and Vasiliki (for the most part) was working alone on her Breathing Wings. As the projects progressed, in the third anchor point, both projects came together and started to discuss and share insights and finally in the fourth and final anchor point the process of sketching with each other's bodies began. Since the projects are still ongoing this phase will continue, as the prototypes become more stable, we will invite colleagues and eventually others without design knowledge for input. The projects share some similarities: primarily they do not have a functional goal, instead the goal is to create body awareness, direct attention and create interest through interactional experiences. The prototypes are designed to support users to make their own choices and define their own "goals" in the interaction space they open. They make use of the same technology to cater for the aesthetics in the body interactions; soft, flexible shapechanging shapes making use of pumped air.

\subsection{Pelvic Chair}

Anna and Madeline were drawn together by a question that interested them both-what would Labella [2] look like if it had been approached as a soma design project? (Labella is a mobile application that Madeline had worked with Teresa Almeida previously which aimed to bring knowledge of the pelvic floor to its users.) Both Labella and now the Pelvic Chair were designed in response to the issues that weak pelvic floor muscles can cause, for example incontinence, prolapse, involuntary flatulence, and pain $[12,40]$. Weak pelvic floor muscles can hinder people from living their life to its fullest [42]. Studies have reported social isolation, anxiety, and depression as a consequence of weak pelvic floor muscles [29]. The Pelvic Chair is being designed using shape-changing interactions and technologies that will interact directly with the intimate and often neglected area of the pelvic floor through its seat, using dynamic movements to create a carefully designed subtle interaction.

\subsection{Breathing Wings}

Vasiliki started designing the Breathing Wings wearable for exploring possible paths to raising awareness and putting attention to the area of the shoulder blades, through shape-changing interactions and technologies that offer a variation of "touch" qualities on this-often neglected-bodily area. It covers mainly the upper back area, extending from the neck to the lower waist, and it has 
SKETCHING WITH THE SOMA

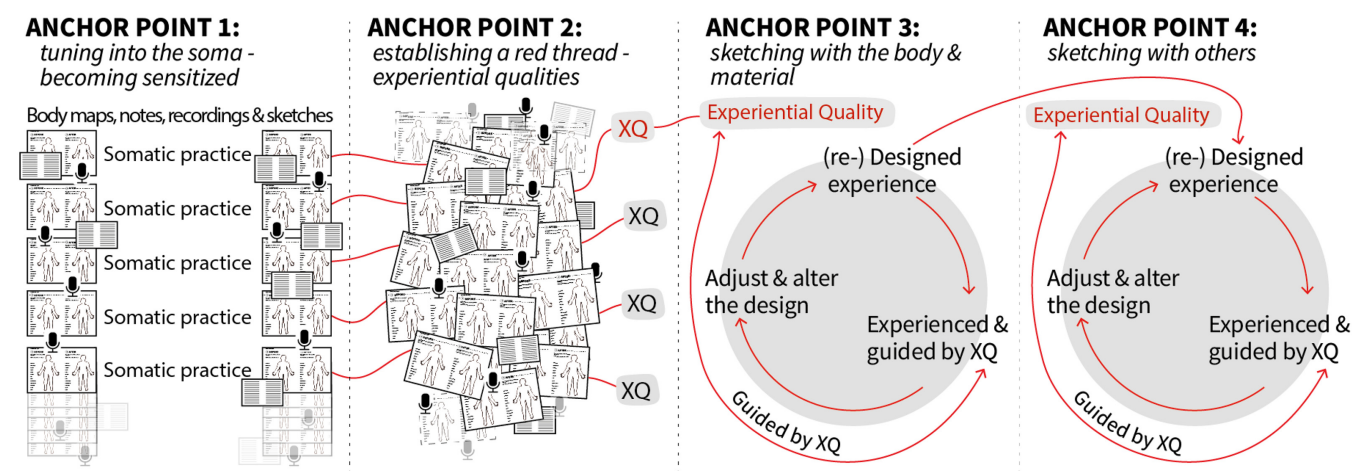

Fig. 2. How the four anchor points relate to one another in a sketching with the soma process. For reasons of clarity only one experiential quality (XQ) is shown in the two last iterative anchor points.

pockets covering the shoulder blades, where shape-changing materials are placed. Studies have shown touch to be a powerful medium and of importance for our emotional well-being [23, 31]. The back, together with hairy parts of our body are parts of the body that quickly assess the pleasantness of touch sensations [45]. The Breathing Wings, similar to the Pelvic Chair, contributes to, and exemplifies the design of carefully-crafted somaesthetic experiences arising through shapechange touch interactions felt on the skin, and developed following soma design methods.

\section{AN ANALYSIS OF A SOMA DESIGN PROCESS: SKETCHING WITH THE SOMA}

Throughout our design process, we made notes about our bodily exercises, and material and soma sketching. These notes aimed to richly describe the process-things we had tried-as well as our somatic experiences. We also made illustrations, and then later low-fidelity physical prototypes, which marked our progress and became materials we could use to discuss, experience and refine. These constitute our "data". The slow development of the prototypes, the tinkering, the multiple iterations on exploring the technology and the data collection happened continuously through different media such as textual notes, video recordings, and body maps [46].

From anchor point three and onward Anna, Vasiliki, and Madeline began meeting roughly twice a month. We used these sessions to provide feedback on the design work and describe our own somatic sensations, as well as share material knowledge and skills. We also used these sessions to discuss our design processes, to review collected data, and begin to collaboratively analyse and identify the key points in our soma design process. There was no strict protocol followed for analysing our data, as it was deemed more important to reflect on first-person experiences at the meeting between shape-change materials and the soma, which is a common approach in soma design methods [65]. This process was grounded by the main aims at driving our process, creating awareness of the pelvic floor, and awareness of the back through touch. This data together with abstracted experiential qualities served as an anchor to guide us in our design decisions, and to critique our process, while navigating this new design space.

In design research practice rigour means careful, critical, thorough and explicit reflection on one's work, based on design judgements rather than following a strict method [53]. Additionally, as articulated in [38] design processes entail failures and successes along the way, which is the way such processes become validated, through the designer/user and their subjective attitude, aesthetic sensitivity, politics, taste, values and bodily experiences (p.9). In our research processes, we were 
regularly returning to our data and using our experiential qualities as a guiding lens, where the goal was to find commonalities, new unexpected insights, and disruptions. This process of design judgements [53] or reflection-in-action [58], is central to design processes, and served as a form of validation and critique for our design choices based on the autobiographical data gathered along the way. Our subjective review of our gathered data guided us to decide on how to proceed from one stage to the next, and consequently to open up the design space. The anchor points that we use here to present how one can sketch with the soma do not solely build from these two specific soma design processes presented. We have seen these pattern of anchor points emerging and reoccurring in our previous soma design projects $[61,62,65]$, though they have not been articulated. In reflecting on the design processes described here, this pattern once again occurred, and as such we felt it useful to articulate the anchor points for others, an overview of which is presented in Figure 2.

What follows is the result of this analysis, alongside practice-based knowledge developed from delivering previous soma design projects, and teaching soma design to masters and $\mathrm{PhD}$ students We share close, autoethnographic details of the first-person soma design approaches we used in designing the Pelvic Chair and the Breathing Wings. Through rich and evocative accounts of our design processes, we contribute to a gap in current literature in design by articulating how soma design happens, and in detail how the soma is brought into the design process. In particular, we wish to showcase how outcomes from first-person methods, and explorations of materials are bridged into design. The thick descriptions [28] that we present have been assembled based on our shared notes, illustrations, photographs, voice recordings, and somatic memories. These thick descriptions have been chosen since they can strongly illustrate for the reader the most salient aspects of our somatic, first-person methods throughout this ongoing process.

Of course, all design processes are unique, and as such, what we outline below should not be considered a "recipe" for doing soma design, but rather instead a series of anchor points that can create an understanding for other designers as to how to utilise first-person methods and material explorations in order to achieve soma design. Although, we present these anchor points in an order, the process should be seen as very much iterative-we move between phases, going backwards and forwards through them as we learn more, and know less. Both projects are still very much "in progress", and the design work ongoing.

\subsection{Tuning Into the Soma-Becoming Sensitised}

When engaging with soma design methods it is critical to use the designers' somas as a starting point for design, which was also the case for the two design processes being in focus here. Having the soma as a concrete point of departure, the design process unfolds over time by coming back to it-thus beyond being the "starting point" it is also a way to continually critique and reflect on the design process.

4.1.1 Pelvic Chair. Anna and Madeline invited a physiotherapist, who was also a trained Feldenkrais practitioner to lead three two-hour long workshops (Figure 3(a)). The practitioner was based in Stockholm and was known for delivering a series of Feldenkrais sessions aimed at providing individuals with pelvic floor awareness and support before and after birth. We explained to the practitioner that we wanted to find ways of connecting to and experiencing the pelvic floor as a starting point in our design process. Our goal in undertaking these sessions was to, in some way, become estranged from our bodies [69], to experience them anew, and differently, and through this identify evocative somatic experiences that we can then use as a jumping off point for our soma design practice. We audio recorded the Feldenkrais sessions so that we could return to them as necessary throughout our design work. The following thick description comes from Madeline's 

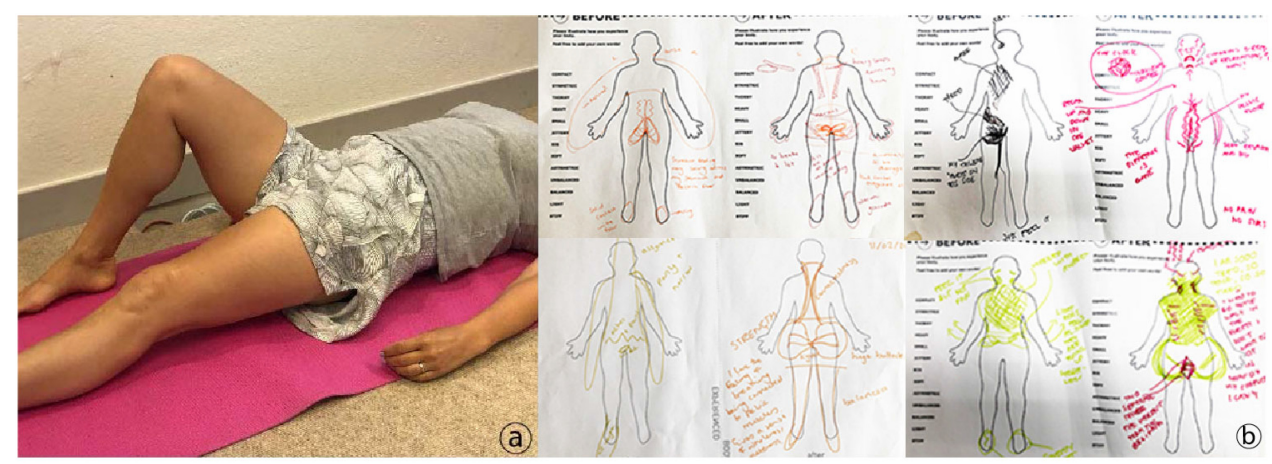

Fig. 3. Becoming Sensitised on the Pelvic Floor area: (a) "As we lay on the floor in a series of Feldenkrais exercises we start to explore small movements of the legs and hips", and (b) a collection of body maps where Madeline and Anna articulated their Feldenkrais experiences.

notes and body maps produced after these sessions (Figure 3(b)) to help illustrate the role these sessions had in allowing us to develop somatic appreciation of our pelvic floors.

"This session has been really eye-opening for me. For the first time, I think in my whole life, I felt my pelvic bones, and really come to understand the size and strength of this part of my body. To do something as simple as sit on your hands and feel the bones and learn something totally new amazes me. The bones feel HUGE. And, now I finally understand what the surgeon has been talking about in terms of where the damage is in my pelvic muscles. I can visualise how the muscles ought to connect. As we lay on the floor in a series of exercises we start to explore small movements of the legs and hips, as we at the same time think about how the muscles in the pelvic floor are moving together or separately to support these movements (Figure 1(a)). The practitioner asks us to make very small movements, which increase the distance between the floor and the cox-sic (or tailbone). As we tilt the pelvis up we also contract the muscles in the back of the pelvic floor-they become the motor of this movement. The practitioner tells us it is just as important to let go of these muscles as we bring our cox-sic back down to the floor. We do these small movements over and over again for maybe five minutes, breathing, contracting, and relaxing the muscles at the back of the pelvic floor. The practitioner talks gently the whole time, reminding us to breath, and drawing attention periodically to different parts of the body. Is our jaw tensed? Are our stomach muscles helping us make these movements? It is strangely tiring, and hypnotic. I experience a deep connection with my body. I become fascinated by the fine control that I can exert of my pelvic floor. I can independently control the back, front and right-hand sides of my pelvic floor muscles. What had been described as "hugely damaged", I realise I can feel where I have strength in my muscles, and I can feel where the damage is."

After each of these sessions, Anna and Madeline completed body maps to capture how these exercises changed their experiences of their somas, if at all (Figure 3(b)). Oftentimes, they discussed their experiences directly after each session, highlighting for each other notable experiences, and things they considered, at the time to be aesthetic. About halfway through the Feldenkrais sessions, the practitioner gave them an alternative, and less somatic entry point to knowing about the pelvic floor. Using a well-known medical textbook, she introduced them to the correct terminology for 
the various parts they were exploring throughout the sessions, and helped them to map some of their somatic experiences onto the visualisations in the book.

4.1.2 Breathing Wings. In the case of the Breathing Wings, the initial point of departure was to explore ways of connecting to and experiencing the area of the upper back and shoulder blades. But also to explore what somatic experiences could be designed using shape-change actuation on this area of the body. Vasiliki used her own body as a point of departure for this exploration, having as an end goal to design for others (other bodies and other people). Starting from a relatively broad design inquiry, it was deemed necessary to zoom into this bodily area and become attentive to it Before embarking on the process of developing the Breathing Wings, and parallel to it, Vasiliki has done several sessions of Feldenkrais and Contact Improvisation that are commonly used in soma design for helping to sensitise one's body [70]. Inspired by exercises used in both somatic practices, she used the metaphor of "touch" as a way of becoming sensitised and of expanding her understanding on the anatomy of her upper back. In Feldenkrais, particular exercises focus on experiencing individual parts of the body, their interdependency, and how they work together to form an experience of a whole, by becoming attentive to individual body structures, through touch, like feeling each vertebra and how they together form the whole spine or the different parts of the fascia connecting our inner organs and limbs. In Contact Improvisation, this experience becomes even stronger, through exercises of touching, holding and carrying the weight of another person's body part (e.g., arm as they are laying on the floor), or when pairs interact with each other through touch and movement, interchanging the roles of leading, or following a movement.

In the following thick description, Vasiliki describes how she went about "tuning into her soma" through touch, aiming to gain an expanded understanding of this body area, in addition to opening up the space of designing new somatic experiences for the upper back and shoulder blades.

"I consider my upper back and shoulder blades as a somewhat "forgotten" area on my body: I cannot easily touch it and even if I can touch parts of it, when I stretch my right-hand on the left side of my back and my left hand on the right, I do not have a full picture (neither visual nor tactile) of the anatomy in this area. Are my shoulder blades big or small? Are they symmetrical to one another, or not? What is their three-dimensional form and shape when one sees my back? In order to gain a better understanding of the anatomical structure of this area, I invited Anna to touch me subtly and hold her palm there for allowing me to feel the anatomical structure through her palms placed on top of my bones and skin. Through her touch, I slowly started to become more attentive to its three-dimensional shape and form, as I could almost "see" my bones protruding and feel how the shoulder blades expand to my arms (Figure 4). As a next step, I invited her to trace the outline of my shoulder blades on a thin, transparent paper that she placed on top of them. Through the felt experience of the thick pen touching my skin, while Anna was tracing the outline of my shoulder blades-an experience felt almost like a slow stroke on the surface of my skin-I could almost "see" their shape and imagine their size. As a next step, I combined this sensitising experience with me taking the role of the person "turning into" and zooming into another soma, by doing the same to Anna: I observed and payed close attention to her shoulder blades, through tracing their outline on a thin, transparent paper. Combining the felt and imagined experience of the shape, size, and contour of my upper back evoked through Anna's attention to my body, with the experience of me zooming into her body, was a crucial step in gaining a first-person experience of the anatomy of my upper back and shoulder blades." 


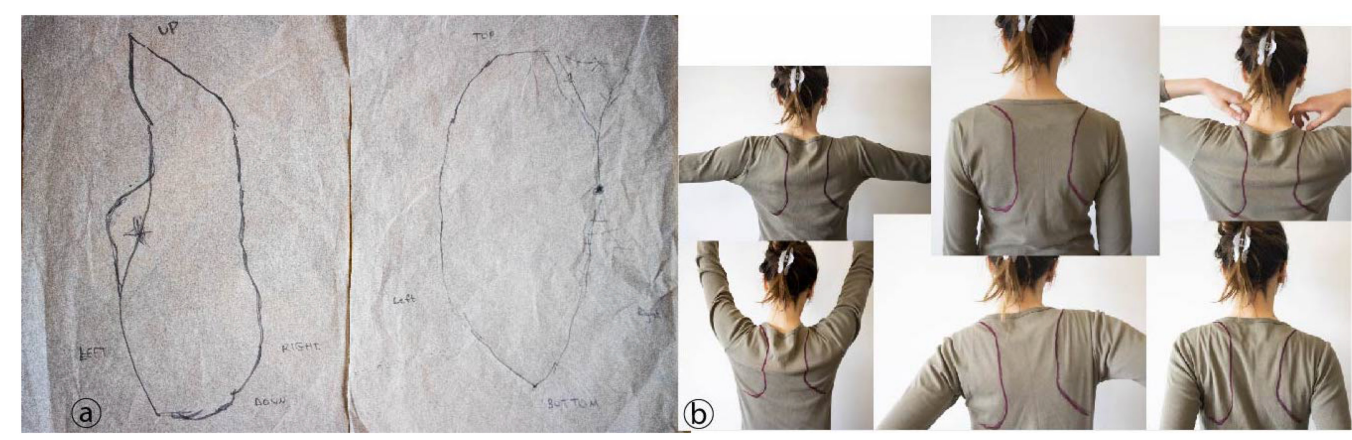

Fig. 4. Becoming sensitised on the upper back and shoulder blades area: (a) "I invited Anna to trace the outline of my shoulder blades on a thin, transparent paper that she placed on top of them (...): I could almost 'see' their shape and imagine their size", (b) Zooming into this bodily area by feeling and seeing the outline of my shoulder blades.

A new finding for Vasiliki arising from these sensitising experiences was that her right shoulder blade is quite smaller than the left one. Additionally, she observed that subtle movements of "pushing against" Anna's palm, when touching her back, was a way of becoming attentive to smaller areas on her back. Subdividing her upper back into smaller areas of interest, allowed her to start discerning how different areas responded to touch. These experiences were documented in body maps in order to be able to come back to them, and which were also used in later discussions and sharing of experiences with Madeline and Anna.

\section{2 “Establishing a Red Thread”: Design and Experiential Qualities}

A soma design process that draws on first-person perspectives is not a "random" process. Similar to any other design process, when doing soma design there is a set of initial requirements or guidelines that are set towards the beginning of the project, and which serve as guidance and as an anchor throughout the process. However, rather than prescribing how the final design should be, or what it should do, such guidelines serve the purpose of helping the designer to follow "the red thread" of working with the body, while helping them to stay close to the soma. The soma designer, therefore, uses their first-person experiences, and the way these experiences evolve and change over time to help them identify and articulate a series of experiential design qualities that they want to exist in the final design. These qualities reflect what somatic experience we should aim for, and can achieve to a desired extent. These design qualities should both be guiding in the design process, held by the design and experienced in the design. These abstracted experiential qualities give us the freedom to not simply mirror a Feldenkrais lesson or a Contact Improvisation exercise. They open up the design space by allowing us to come up with design ideas and explore materials with different affordances but which when carefully combined still resonate with the original qualities of the desired somatic experience. In this sense, the route to an experience can be multiple and is dependent upon the judgements a designer makes in the design process. The experiential qualities are there as something that one needs to keep coming back to as the process unfolds, guiding and supporting reflection and evaluation of the process and later of its outcome. Thus, rigour in soma design is tightly coupled to "staying with the qualities" and making sure they are there throughout the design process and in the final product. But how are these design qualities set or defined, and by whom? As we show in the next two thick descriptions they are set by the designer(s) and are generated based on their first-person somatic experiences, and in particular, use of estrangement methods. 
4.2.1 Pelvic Chair. After taking a break of several weeks, we repeated several of the sessions using the audio recordings. This repetition was vital since it allowed us to realise, which experiences continued to be evocative and aesthetic, and which were perhaps less interesting or engaging when tried for a second or third time. Again, we used body maps before and after these sessions to help us notate the somatic experiences that these exercises led to. This process continued over several weeks, depending on when we had time in our working days to engage in these activities. During this time, we also both touched and felt our own pelvic floor muscles and skeleton in order to try and sketch this area of our bodies. Eventually, we sat down together to discuss what we had found to be evocative and to try and identify the design qualities that we thought we could design around, and thus the beginning of the "red thread" for this project. Using our body maps as a reflective guide, we discussed our experiences, focusing in particular on what we found to be important experiences that had the potential to be meaningful over the longer term. This took quite some time as we tried to describe verbally the experiences we had, and why we felt these experiences were important to capture in a piece of interaction design.

We both found the awareness derived from touching different parts of our pelvic bones to be incredibly powerful-not only in terms of recognising the size and strength of this part of the body, but also in terms of understanding the anatomy of the body, how the pelvic floor muscles are connected to the skeleton and how these muscles work together to keep many organs in the right place! For both of us, we found this touching of the skeleton to be quite a foundational experience, something that had helped to get us in the right "place" for further discovery, since it had so strikingly orientated us to our own bodies. We discussed this as "unitedness".

This foundational awareness of the orientation of the pelvic floor and the experience of how the skeleton collaborates with the pelvic floor muscles were gathered in the XQ, "unitedness" (Figure 2). We were also fascinated by the ability to be able to divide and control parts of the pelvic floor muscles independently-the front, the back, the left, the right side, and even finer details. This sense of newly found control was very satisfying and in some ways enriching (particularly when parts of the muscles are damaged or weak), since we felt that it continued to help us both to understand how these muscles are structured within the body, and how each segment of these muscles can become a motor for several different movements. We termed this quality "differentiation". Then, for Anna much more than Madeline, the sense of deep relaxation achieved throughout some of the sessions with the practitioner were enlightening. Anna had not realised the extent to which these muscles are always tense. Through working with these exercises Anna began to understand that the muscles have so much more length in their fibres to work with if you also relax and use the whole muscle groups' potential. So, becoming aware of and understanding how to relax the pelvic floor was a strong and memorable sensation. Madeline on the other hand, perhaps because of the damage she has sustained to her pelvic floor, found that she could not connect so strongly with this experience. She found it pleasant, but not "world-changing" in the way that Anna seemed to find it. Together, they started to talk about this quality as "relaxational power". And, although Madeline did not connect strongly to this XQ herself, through discussions with the Feldenkrais practitioner and with others present during these sessions, she understood that this could be something interesting for many to experience with their bodies.

We both held extremely positive experiences and memories of several exercises, which had been focused on showing the connection between the pelvic floor muscles, abdominal muscles, the diaphragm, and the oesophagus. We were shown how to notice and use the ways in which the muscles work on the horizontal plane in the body; that we can connect the pelvic floor movements to our diaphragm movements when breathing. There was something very meaningful about this 

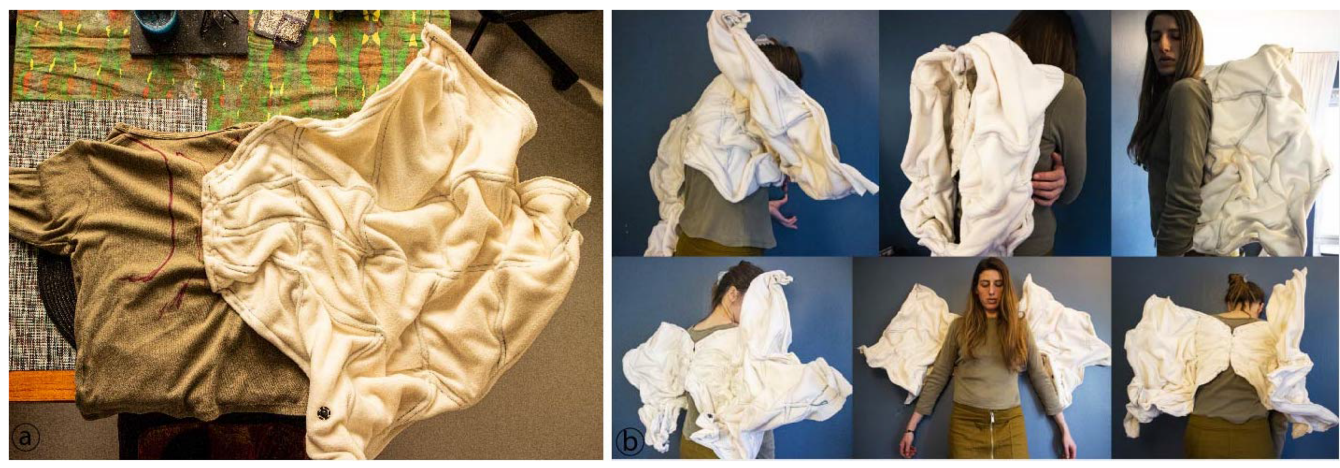

Fig. 5. Exploring the spectrum of somatic experiences on the upper back area, by engaging with enstrangement methods: (a) Vasiliki made a pair of wings attached to a blouse, and (b) wearing the wings and reflecting on her first-person experiences evoked through this "other thing" touching her back.

experience. Madeline looked back at her body maps, and described how this experience gave her the sensation of being "whole" or "complete", and powerful, something like a super hero. Yet, it is hard to pinpoint why or how being able to synchronise movement between the pelvic floor, diaphragm, and oesophagus would be able to lead to such a feeling. This experience we started to refer to as "connectedness".

Finally, we noted how the Feldenkrais practitioner, through asking us to make small movements, which changed every now and again, and through the questions she gently posed throughout the sessions had helped us to tune in and out of different parts of the pelvic floor, allowing us to remain engaged and aware of our bodies across several hours. This reminded us that the interaction has to build up in stages, and that we need to make use of interest and change to create awareness.

4.2.2 Breathing Wings. Moving from becoming sensitised to the area of the upper back and from gaining a deeper understanding of its anatomy, Vasiliki sought to identify what particular experiences would be evocative to design for. Continuing to have first-person reflections at the core of the design process, she used the "wings" as a metaphor and guidance for identifying the experiential qualities of interaction she was after. Returning to experiences of having another person touching her back, which led to an expanded and nuanced awareness of how the bones and muscles around the shoulder blades are connecting to one another, she took the sensitising activities one step further and combined them to activities of estrangement. She started wearing a pair of custom-made wings, aiming to reflect on the somatic experiences evoked through having this "other thing" attached to her back, as a type of body extension or "person" touching her back, although inanimate (Figure 5). She made the wings from metallic wire and thick textile, in order to provide her support on the upper back through their weight when wearing the straps holding the wings close to her back. In the following, vignette she provides an autobiographical account of this process and experience.

"I attached the wings on a blouse, making sure that their base was touching and following the outline of my shoulder blades, to evoke a sense of "touch" in this area. Initially, I wore the wings for two days, for about three hours per day, while being at home and doing what I would normally do. I deliberately designed them in a way that they would have some weight and expand in space, facilitated through a wire structure stitched inbetween two layers of thick textile. The sculptural-like formation of the wings made it possible to bend them and change their shape, e.g., to imitate expansion outside my 
back or retraction close to my back, as if they were "closed" or "opened". Reflecting on this extended perception of my body it became immediately apparent how much more space my body took. I could sense the exact location on my back where the wings were attached and I gradually started becoming extremely aware of this area. This was a result of the wings extending from that location, while at the same time pulling me slightly down, since my centre of balance had shifted while wearing them. I started enjoying having this "foreign body" attached to my back and I caught myself at times moving slightly from side to side or back and forth, as a way to re-affirm that the wings were there. But also as a way to "talk back to them" and provoke some kind of (imaginative) conversation between my body (through my shoulder blades) and the wings. Feeling their extra weight sometimes was perceived as pleasant (a feeling of being more grounded on earth), but sometimes it felt heavy and tiresome. When sitting on a chair, feeling "touched" by the chair through this foreign body attached to my back, felt like a nice stroking sensation on my skin."

This experience deriving through somatically exploring the poetic metaphor of having wings attached to my back, as an extension of my body, became a pivotal phase in the design process. It served as an anchor for identifying the design qualities that should be put into focus, serving as a "red thread" for this project. This process continued over several weeks and I used my autobiographical reflections emerging both from wearing the wings and from reflecting on past experiences of Contact Improvisation exercises I have done. I started noticing that the strong material presence of the wings on my back, not only contributed to becoming attentive to this bodily area, but also evoked experiential qualities similar to those I have observed in particular exercises. Two experiences helped me to make the design and experiential qualities concrete at this stage: Weight or touch applied to my body through another body (human or material), and counter-balancing my body weight by the weight (or physical presence) of another body touching me (either the wings, or another body in Contact Improvisation).

Reflecting more deeply on these two experiences, one thing that became notable during this design phase, was that having something or someone touching my back at the area expanding from the trapezius muscle to the scapula bone, was an experience that both created awareness of how the muscles and bones in this area connect, and also caused a soothing effect of relaxation. This experience was stronger when another person's palm was placed on the upper and middle trapezius muscles, covering a substantial area on my upper and middle back. Apart from being an experience that "created an awareness through touch", this was also articulated as a design and XQ of "being held". It was not only the fact that there was something touching me empathically, but it was the fact that there was a slight pressure or warmth felt when touch was applied, that contributed to an evocative and aesthetic somatic experience on this area on my body.

More broadly, the experience of "being held" also resonated with my past experiences evoked through bodily exercises I conducted in which another person touched my back gently or lifted and held parts of my body in their hands (e.g., arm or leg). This increased the awareness of the body part being held, and it also "felt nice" as there was trust built between me and the other person holding me, and there was a feeling of being taken care of by someone else. Thus, another design and XQ that was set at this stage was to aim for an interactive experience that would evoke a sensation of "being taken care of". This design quality was deemed rather abstract and subjective, but was there to remind me of aiming to design for trust and intimacy. I imagined the Breathing Wings to evoke an experience of being taken care of, while supporting the wearer to become attentive to their soma, and to provide a space for reflection and appreciation through the shape-changing interactions. 
Emerging from the first-person experiences of wearing the wings that helped me to expand my initial perception of the anatomy on my upper back and to become more attentive to this area on my body, another quality became central in the design process; that of "feeling embraced". Unpacking this design and XQ, aiming for an "embracing" experience when wearing and interacting with the Breathing Wings could arise through the properties of the materials: primarily through the shape-change materials that I introduced in my design process as a next step, but also through the materiality of the wearable when surrounding the body.

\subsection{Sketching with the Body and Materials}

The very nature of soma design means that you have to work with matrials and your first-person experiences. It is not sufficient to try and use only words to describe your experiences, and particularly experiences with prototypes and materials. Prototypes (starting of course with very low fidelity ones) need to be made so that you can use and train your somatic skills so as to be able to judge whether the emerging prototypes are leading to the kind of somatic experiential qualities considered important (the red thread). A designer engages with physical and digital materials through their body, meaning that first-person experiences and judgements are the starting point and the point of return for validating a process of working with materials. This stage of the design process is driven by questions such as: What felt experiences does this particular actuation technology evoke on the body? and focuses on how to give form to such experiences, aiming to design for the qualities identified (e.g., for evoking an experience of "being held" or "being taken care of" in the case of the Breathing Wings described previously). However, it is important to note that at this stage the aim is not to replicate the experiences of somatic practices with the digital materials being in focus, but to explore designs that can hold the abstracted experiential qualities from the previous design stage. As in every process that includes hands-on explorations with digital and physical materials, the designer first engages with those aims at exploring their inherent qualities and the experiences they evoke on the soma (in this case), before moving into shaping the material affordances for the particular design context and aim. Thus, a designer has these experiential qualities in mind, but engages with materials with an open mind, allowing materials to communicate their qualities. In the processes followed for developing the Pelvic Chair and the Breathing Wings, we wanted to convey the experiential qualities that had emerged from becoming attuned to our somas through exercises performed, not to mirror these. By exploring shape-changing materials on the body and by getting to know their affordances, we aimed to scaffold a space for exploring how our qualities could be experienced anew, through these materials.

4.3.1 Pelvic Chair. We wanted and needed to move away from articulation in words to instead go to sensing and actuation directly on the pelvic floor muscles and pelvic skeleton. Only by doing this could Anna and Madeline direct attention to developing the kinds of interaction they aimed for and that would deliver the experiential qualities that they set out to achieve. Madeline and Anna had already explored heat and vibration in earlier designs $[62,70]$ and had begun to make some early explorations with shape-change. We were curious about what shape-change could give and how it could create a sensation of touch (while also not mimicking human touch), and whether through "touching" the pelvic floor muscles, we could create the awareness and appreciation of these muscles and anatomy that we considered could be "world-changing". Anna expressed this as follows:

"The similarity to Labella does not only come with body literacy as in understanding what is where, but an experienced body literacy, as in awareness of tensing and relaxation and overall awareness and appreciation. Also, most important is that it puts a layer/filter between you and your body exploration. As Labella with its hand-drawn 


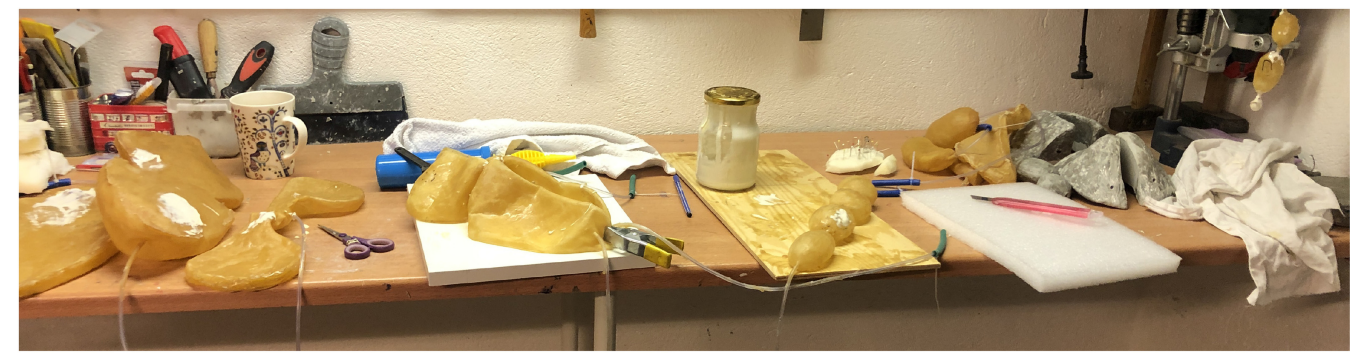

Fig. 6. Working with clay and latex for developing custom-made shape-change shapes that could be inflated and deflated through an Arduino Pneumatics circuit board.

illustrations instead of a camera, or real pictures make it too intimate. This shapechange allows you to be touched and touch without using other parts of your or someone else's body."

Part of the earliest design work was to identify the right materials for actuation on the body. Our explorations began quite simply-selecting existing shape-change technologies from the lab's workshop, and placing them on the body and pelvic floor to evaluate the kinds of touch these technologies might give. Our explorations included linear actuators, and air pneumatics with both non-elastic and elastic shapes. We found that both the linear actuators and the un-elastic soft shapes did not follow the shapes of the body very effectively. As we pressed these against our bodies (specifically our stomachs, hips, and sides), we both found that these gave the sensation that only a small part of the shape is actually touching your body. It becomes a very "pointed" kind of touch. We did not consider that this would be pleasant when used on the pelvic muscles We needed something, which would follow the curve of the body. We experimented with silicone and latex (Figure 6) (first balloons and then our own custom made shapes). We found silicone to be more rigid as a material and harder to cast around any shape and seal if you would want to fill a shape with air. In contrast, latex is very flexible and durable and can take on almost any form. It also allows for sealing, cutting open, and resealing again.

Anna gave a chair-like form to our design work, so that we would have a form factor that could support us in using our first-person, somatic design judgements as part of the design process (Figure 7(a)). A chair seemed like the most appropriate form factor, since we considered that it would allow us to create an interaction where the pelvic floor could be touched, and where the person being touched could be relaxed, comfortable, and feel safe. Anna utilised available ergonomic data to purposefully design the shape of the chair such that it could accommodate a wide-range of body sizes. The design started initially as something like a stool, and to make the most contact with the pelvic floor area it developed over time to something more like a stool/horse saddle hybrid (Figure 7(c)). Our first experiments with the chair began with differently sized balloons placed underneath a layer of foam, which were balanced upon a stool, and which could be sat upon. The balloons were hand-pumped to give a sense of interactivity. Anna's early remarks focused on whether the choice of material was given the quality of touch that we were aiming for:

"The elasticity against your pelvic floor can create the sensation of being held or embraced. It embraces the body flesh rather than pokes it, it is not restricting you, but allows for the body to still move. It allows for some negotiation of control and agency."

We became satisfied with the choice of latex combined with foam as a kind of mid-way prototype that would start to allow us to start defining and exploring some of the interactivity that we wanted 

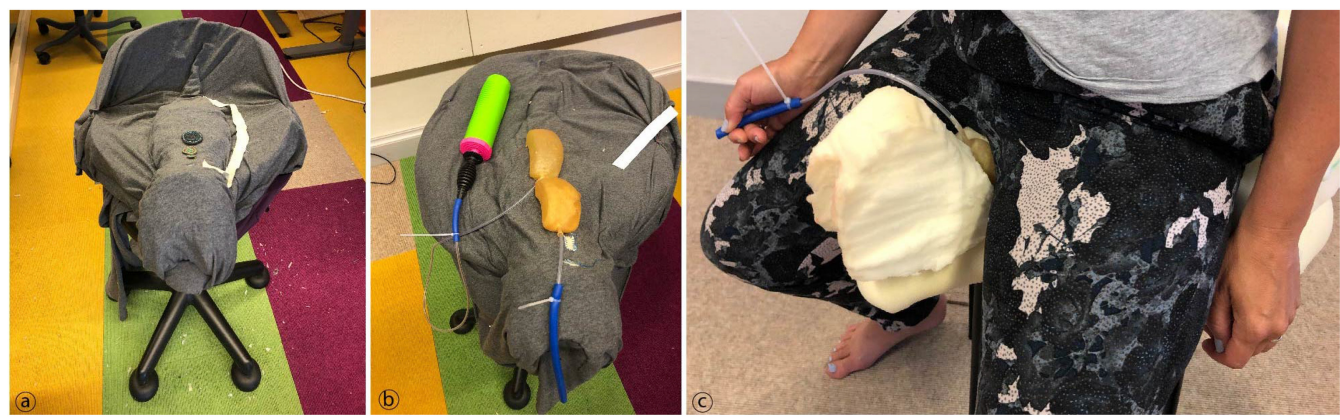

Fig. 7. The design of the Pelvic Chair started as a stool and developed over time to something more like a stool/horse saddle hybrid. In (b) and (c), latex shape-change materials are experienced while being manually pumped with air.

to design for. Our experimentation moved on to examine the sizes and shapes of "shape-changing modules" that we required to create awareness and appreciation of the pelvic floor (Figure 7(b)). Our experimentation was usually held in our open plan office or in Anna's basement, with one of us sitting on the chair with their eyes closed trying to concentrate on their soma and the experiences unfolding with their pelvic floor muscles, while the other knelt in front slowly inflating, holding, and deflating sometimes several inflatable latex shapes at the same time. In one design session, while Anna sits on the chair, Madeline is pumping up several latex shapes underneath Anna. Together they are trying to determine a sequence of inflations and deflations to create a sensation of relaxation. As Madeline pumps the latex shapes, Anna has her eyes closed. She says "I think that's enough" and Madeline stops pumping the shape and instead holds the air in the shapes by pinching hard on the tubing. Some time passes, and then Anna nods. Madeline begins to deflate the shapes in sequence, releasing her grip on the tubing. The air whooshes out faster than Madeline anticipated and Anna shrieks and begins laughing. She explains that the quick deflation gave her the sense that she might wee. We try the set up again. This time Madeline being careful to release the air less quickly. As the air slowly leaves the latex shapes Anna's whole face relaxes, her head drops to the side, and she lets out a sigh. A few moments of silence pass. Finally, Anna opens her eyes and says: "That's nice. That's relaxing." The discussion between Anna and Madeline moves on to talk about the specifics of the shapes, the sequencing of deflation, and how to achieve this with high fidelity materials. In bursts of activity like this, we used different sizes and strengths of shapes, different widths of foam, and different configurations of inflation and deflation.

The prototype chair gave the direction for where to go with our latex shape experimentation and the need for shapes that were tailored in shape for the pelvic floor interaction. We learnt that bigger soft flexible balloons do not restrict your movement, make you lose control, or feel pokey. Anna notes:

"When designing for intimate touch through shape-changing interaction, we sketch with the material(s), using its affordances, shape, volume, and placement on the body together with temporality to shape an interaction. Since this interaction is physical and directed to a specific place on the body, it cannot be evaluated based on how it looks visually or feels under our palms, it has to be experienced through and with the intended body part. We are less used to actively sense and evaluate with and through our pelvic floor and it requires a lot of attention. We have noticed during our design experiments where we experience the on body interactions that we get very tired from attending awareness and sensing through body parts we are not used to." 


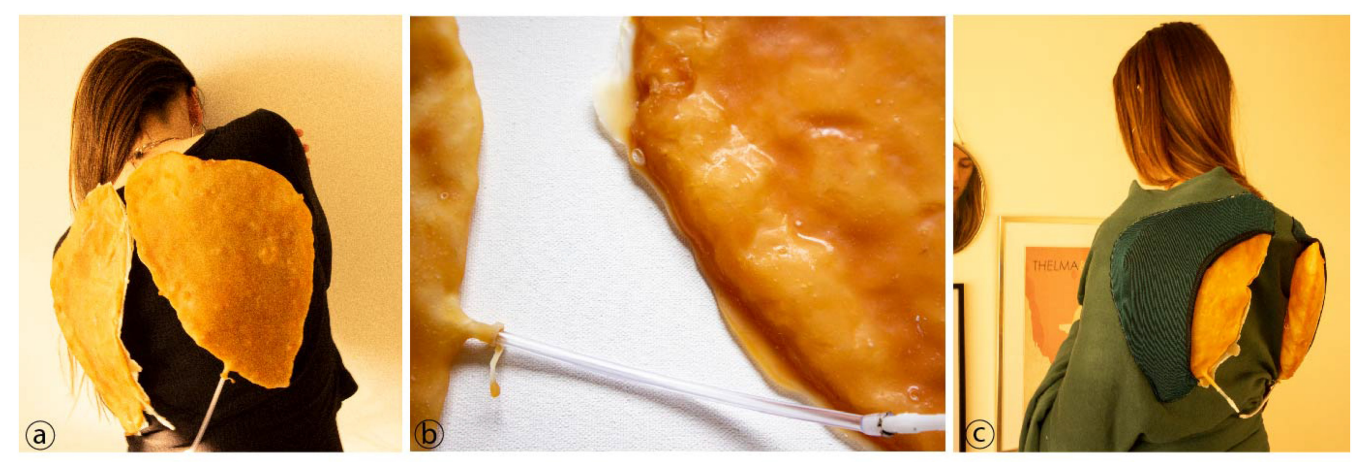

Fig. 8. The Breathing Wings (from left to right): (a) The two big shape-change latex shapes touching Vasiliki's upper back, (b) A close-up of the shape-change latex materials, and (c) Wearing the Breathing Wings.

4.3.2 Breathing Wings. Similarly, in the case of the Breathing Wings, the design process moved from the articulation of the design qualities with words to exploring them through materials and the body. Together with Madeline and Anna, I had already explored heat and vibration in earlier designs and I was curious about what shape-change could give and how it could create a sensation of touch, helping to raise awareness on the area surrounding the shoulder blades. Compared to the Pelvic Chair process described above, instead of exploring shape-change actuation through balloons first, I directly started developing shape-change shapes with latex to experience their effect on my body. This was because I was following an autobiographical process of working mainly alone, which made it hard to both experience and control manually the air exerted through balloons. Experiencing the shape-change latex shapes was easier as our research group had developed an application on a mobile phone for controlling manually their inflation and deflation. Together with Anna, I slowly developed and mastered a process of making shape-change latex bladders in any shape and size. Each latex shape was connected to an Arduino Pneumatics system through a plastic tube, and with the help of an application developed on a mobile phone, it could be independently and manually actuated.

I initially designed a pair of rather flat and big inflatable shapes out of silicone, to explore further the qualities of "being held" and of "being embraced", while being touched on the back (Figure 8). I created a simple wearable in which I stitched two pockets where the bladders should be inserted, and I wrapped it around my torso. I played with different patterns and timings of inflating and deflating the bladders, including inflating both together as a synchronous choreography of shapechange, followed by an asynchronous actuation, with one being inflated first, and the other following after five seconds. Below is an autobiographical vignette that describes the most evocative experiences of the actuation felt on my back:

"I wore the latex shapes and started exploring different patterns of inflation and deflation. First I tried to observe and "listen" to their movement. I felt their subtle inflation and deflation almost as a stroke against my flesh. An immediate reflection was that a slower inflation and deflation felt much nicer than a quick one, contributing to a soothing sensation. Additionally, a slow but steady inflation until both shapes were fully inflated, followed by a slow and steady deflation until both shapes were fully deflated, contributed to an increased awareness of my shoulder blades' shape and structure. I verbalised this experience as a "strong presence" of the muscles and bones located on this area of my body, emerging through an XQ of being held and feeling embraced. I gradually started moving my whole torso, subtly, as if I was trying to respond to their 


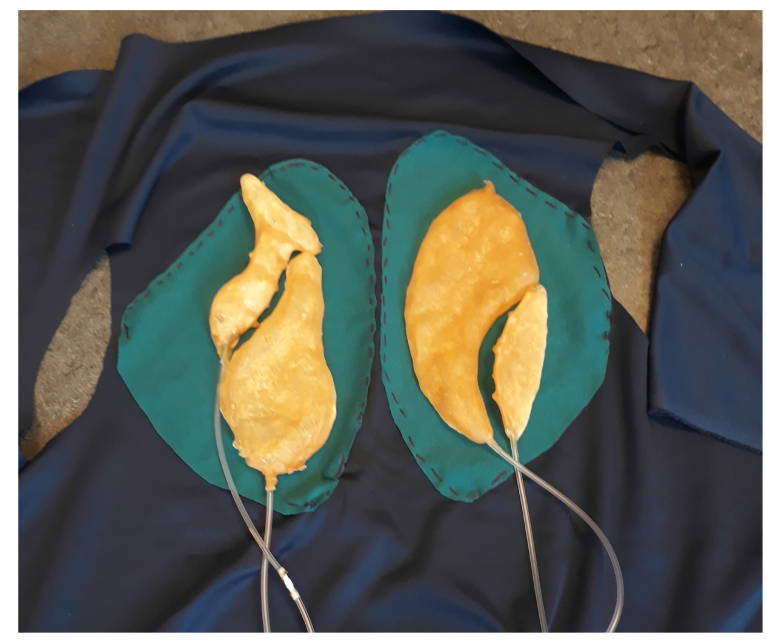

Fig. 9. A collection of four small latex shapes; two for the left and two for the right side of the back. They were made for testing how the experience might be different when subdividing the "touch" applied through the shape-change on the back, to smaller areas.

movements. For a while I only focused on the left bladder, and I started tilting my back towards that side. I suddenly wished for a mirrored experience on the right. The boundaries of body and shape-change materials started to become blurry. Were the wings moving first and I was following, or was I moving first and they were following?"

Continuing the process of sketching with the body and materials, I made a collection of smaller latex shapes; two for the left and two for the right side of the back (Figure 9). This design decision was informed by the need to explore how the experience might be different when subdividing the "touch" applied through the shape-change on the back to smaller areas, and in particular when dividing the lower trapezius muscle from the middle trapezius muscle, "touching" each muscle separately. Following inflation and deflation patterns similar to the ones tried with the two big shapes, and reflecting on the experiences evoked, I noticed that overall the bigger shapes contributed to a more engaging somatic experience than the smaller ones. Even though the smaller shapes were aimed at capturing the topographic nuances of the anatomical construction on the shoulder blades, they led to a "poking" sensation as the inflation and deflation was located on smaller areas. When a shape was inflated too much, the material felt like taking over, almost like pushing me, and then my focus was shifting from my body to the shape-change material instead.

Parallel to experiencing actuation through the shape-change shapes, I started developing different versions of the wearable. Following the red thread of the design and experiential qualities that I was after, the research question driving the process of developing the form and shape of the Breathing Wings was "how to design the wearing experience in a way that would contribute to evoking experiential qualities of feeling embraced, being held, being taken care of?" Working with textile and my body, I decided to make a wearable worn as a type of vest, but which should be "strapped on" the body slowly, by tying two long pieces of textile around my waist and knotting them together in the end. I designed the experience of wearing it almost like a ritual, and I imagined that it would take some time to put on the Breathing Wings, as a way of being initiated to the interactive experience they could offer to the wearer. As I articulated in the following excerpt taken from my autobiographical notes: 
"I slowly start wrapping the fabric around my waist. It takes time, but I do not mind. The process of strapping it on my body makes me feel like I am taking care of myself. It is the journey that matters too; not only the destination. I slowly reach the end. Now it is firmly wrapped around my torso. The pressure around my body feels nice, as if someone is wrapping their arms around me. I am being hugged."

The combination of the somatic experience evoked through the wearable and the shape-change felt on the back started suggesting a sensation of being taken care of through the actual commitment of wearing it. Additionally, when inflating, the shapes were pushing "inwards" on my body, filling in the negative space and curves surrounding my bones. Suddenly the shape-change materials and the body became intertwined, and I started wondering: Where does my body end and where does it begin?

Movement became a strong focus for exploring first, and then for starting designing for the experiential qualities I was after. Thinking about movement I imagined a type of interactive dialogue unfolding between the shapes, suggesting subtle movements, or inviting me to perform a form of choreography with them, by inflating and deflating, pushing and pulling me, leading and following. Awareness and appreciation of the anatomical and muscular structure of my shoulder blades was achieved through touch and movement. What if the Breathing Wings were designed in a way that they would suggest a movement and it would be up to the wearer to follow, or not? Movement could be as subtle and nuanced to an extent that could be almost imagined, as an inviting gesture to participate in something; in a new somatic experience that would help one to re-connect to their "forgotten" shoulder blades.

\subsection{Sketching with Others}

At a certain point in a soma design process it becomes necessary to invite others into the design process, to share one's nascent design prototypes and ideas, and start sketching with other somas. The moment of inviting others is not predefined, but it usually takes place when designer(s) have explored a design space with their bodies and materials to an extent that they have a collection of evocative (to them) experiences that they want to take further. Thus, the time of inviting others to a design process is meant for bridging one's first-person experiences with other people's experiences, and through that aim to critique, judge and validate design decisions while the design process still unfolds. However, the phase of inviting others to experience something is not really a typical "evaluation" of the prototype. Broadening the spectrum of first-person reflections through the perspectives of others is about expanding the somatic judgement of the emerging design, and confirming, in some sense, that the design work speaks to other people's somas, through broadening out the somas involved in sketching. In this phase, both designs are still in the making, the materials are still not really conveying the experiences sought for. Therefore this sharing-at least in our experience-is useful when done with someone who also has experience of using their soma for design judgement, since it requires using the soma in a very specific way in order to experience the prototype and consider what the experience is, and how it could be altered. This sketching with others is a process of itself, as is every phase in the soma design process. To get constructive feedback on something that is in the making, it is more useful to start out with someone who has the specific material knowledge and experiential knowledge to get the nuances of expert feedback. At a later stage, when the design is closer to conveying the experiential qualities sought for, you can bring in someone who is still used to using their soma for design judgements, but might not be so familiar with the project, gradually opening up for inviting others into the sketching process. This phase of work constitutes another opportunity to explicitly come back to the overall aim and the more specific design qualities, through a range of somas, the extent to which those qualities 
are embedded within the prototyped interactions. It should not be characterised as evaluative, but as a continuation of the design process.

In the case of these two projects, which are still ongoing, Anna, Madeline, and Vasiliki came together to undertake the first part of this phase of work. We aimed to meet once a fortnight over several weeks in order to slowly and carefully experience each other's prototypes, experiment with materials and unpick the somatic experiences. There is often so much emphasis on verbal explanations of experience, but here in this phase, it was vital that we could see and respond to one another's facial expressions, body language, and touch, and that we couple these outcomes with critical reflection on the materials in use. The design judgements shared in between us in this phase, led to further refinements of the design and will, when we can meet physically again, open up for inviting others with experiences of somatic knowledge from our design lab to sketch with us. In an iterative manner, guided by our experiential qualities, we are slowly coming closer and closer to a design that could convey the sought experiential qualities (see Figure 2).

4.4.1 Pelvic Chair. The first time Vasiliki sees and interacts with the Pelvic Chair was in the Soma Design room in our lab. We do not do any Feldenkrais exercises or other somatic activities prior to trying one another's designs. We are too curious to see what each other have been working on, and want to get straight to it. Anna invites Vasiliki to sit on the chair and to take her time to position her pelvic floor comfortably to it. Vasiliki verbally expresses that she finds comforting the support and embracement she feels around her lower back and bottom, through the physical form of the chair. As Anna inflates and deflates the shapes beneath Vasiliki, Vasiliki asks "How are you supposed to act on this chair? Is it a more passive experience or should it initiate small movements?", while at the same time she finds herself moving in correspondence with the shapechange actuation of the shapes underneath her pelvic floor. Together, we reflected on the fact that the experience offered through the dynamic shape-change interaction should cater for different bodies and personalities: You should be free to move when sitting in the chair, if you want, and the designed interaction should cater for this scenario and experience. But at the same time, you should be able to have evocative experiences and be able to increase your awareness of your pelvic floor even if you decide to stay still and experience passively the shape-change on your body. A design decision taken at this stage was that the chair, through its inflation or deflation could start a movement or a weight shift on the body that might infer/invite someone to follow this movement. Awareness and appreciation for one's pelvic floor could arise through the support this artefact can offer to that bodily area, in addition to suggesting movements on the different areas on the pelvic floor, which the person sitting could decide whether to follow, or not.

We also started to realise there are several features of the design and interaction that are unclear, and that are hindering Vasiliki in reaching a deeper experience of the chair and its shape-changing qualities. We realised that an important role in designing for rich somatic experiences, and for engaging many different bodies in such experiences, is through carefully designing the way the prototype and experience it offers are introduced to the user. In the case of the Pelvic Chair, there should be some kind of somatic introduction on what you are supposed to experience or do, opening up a space for a person sitting on the chair to be engaged to their desired degree, depending on their bodily knowledge, and curiosity. At the same time, we realised that the way a person sits on the chair has implications for how the shapes make contact with the pelvic floor, and thus, the chair needs to help the person to get into the right position, while also feeling safe, and that this might serve as some kind of introduction to the experience. We discussed that the pelvic floor can be more or less in contact with the area you are sitting on. To allow for touch we designed a chair, which has a curvature along the pelvic floor and a front piece which makes you open your legs a bit. This is something that is a quite unfamiliar pose for a woman, and that can make you feel 
vulnerable and uncomfortable. But in iterations, we found having a front piece there made it feel safe and more like sitting on a horse saddle.

When Vasiliki tries to become attentive to the front/back, sides, or quarters of the pelvic floor through the shape-change actuation felt in each area through the chair, it is hard for her to discern differences. We know that, we need to advance our technology to be able to pump and control the airflow within the chair, as it needs to shift from e.g., front to back faster, so you keep the interest and have something to compare to. Furthermore, as we try to inflate and deflate a sequence of shapes to give a sense of relaxation (something that had previously been quite successful in Madeline and Anna's own explorations), Vasiliki noted that because we are using quite small shapes this requires a really intense focus on the touch, which is very demanding.

We also notice and start to discuss how strange it is to be using our pelvic floor muscles for design judgement. We are not used to using and sensing with these muscles, and we all find that we get exhausted from the attention required. If it is exhausting for us, then it will also be exhausting for other people who sit on the resulting chair, and so we understood even more clearly that these interactions have to be introduced with care. We cannot use what we have learnt in Feldenkrais exercises and try to design for the same kind of body awareness in one interactive session with the prototype. The first time you use the chair it might be enough to just get aware of the pelvic floor area and that you can relax it. And even coming to our sequential air chambers is probably for quite advanced users.

4.4.2 Breathing Wings. The first time Anna and Madeline tried and interacted with the Breathing Wings was also in the Soma Design room in our lab. The wearable Vasiliki had designed was purposefully made to accommodate different body types and sizes so it was easy both for Madeline and Anna to wear it and tighten it around their waist, with Vasiliki's help and guidance. Madeline, firstly experienced the two bigger latex shapes while sitting on a chair. She was invited to keep her eyes open or closed and to relax, while becoming attentive to having her torso surrounded by the Breathing Wings wearable. Vasiliki, who was manually controlling the inflation and deflation of each shape through a mobile phone, started by inflating both shapes at the same time to their fullest, and then deflating them completely, mimicking a type of slow breathing pattern. Madeline, sharing her first-person experiences out loud, noted that she felt like her body was getting smaller, almost like being embraced or, as explicitly verbalised by her, "a bit like merging into a thing".

This experience evoked through the touch qualities of these shapes touching Madeline's shoulder blades reminded her of somatic experiences evoked through particular Contact Improvisation and Feldenkrais exercises (i.e., when another person presses or squeezes their palm or another part of their body onto someone else's body). Madeline expressed that the regular, but also changing rate of inflation and deflation felt against her upper back, evoked a touch memory and sensation described as not being so cautious, but which still felt nice, as it was not intrusive or unpleasant either. Describing the quality of the touch she felt in more detail, she compared it to a sense similar to when a person touches your back with confidence and who also cares for you. When Madeline experienced the smaller shapes, she shared a different experience. The shapes felt rather "pointy" and she expressed that the touch quality they evoked resembled a type of "machine", rather than a human touch, since there was also less warmth experienced on her skin, due to the smaller area the latex shapes were covering on her upper back. However, Madeline did not necessarily find this a worse experience compared to the big shapes, but a different one.

Based on Madeline's experience, we all discussed how the Breathing Wings could initiate the wearer in an interactive experience slowly, by both suggesting and offering multiple choices of how the wearer would respond to this experience, similar to the Pelvic Chair. What would the Breathing Wings want the wearer to do? And, which bodily posture should the wearer assume, in 
order to experience the shape-change in its fullest potential, close to their skin? Should they sit with their back and torso straight or lump and drop their shoulders as if "melting" into a chair? These questions emerging through inviting Madeline to experience the prototype, helped Vasiliki understand that touch experiences evoked through the shape-change latex shapes would differ depending on the wearer's body posture and attitude towards the experienced interaction (be it e.g., playful, exploratory, or cautious).

Anna, similar to Madeline, firstly experienced the Breathing Wings with the two big latex shapes and then with the four smaller ones (two on each side). Initially, she sat on a chair with her eyes closed, having the wearable wrapped around her torso. Now that Vasiliki was more aware that the body posture was an aspect that could affect the somatic experience evoked through the actuation on the back, she was more attentive to Anna's posture. As Anna was sitting with her torso straight up, in a quite "unnatural" sitting position, Vasiliki verbally guided her to relax on the chair. While Vasiliki was inflating and deflating the latex shapes, imitating patterns similar to the ones Madeline experienced, Anna shared that their movement felt as if someone was placing their palms on her back, and then holding them there. She also felt their heat, and she wished for more: for the experience to go on and on. She imagined warm palms that press more and more gentle against her back (while the shapes were inflating) and she shared that she started feeling very relaxed on her back, but also on her whole body. Reading her face expressions, Vasiliki could see that she was enjoying this experience. Anna also mentioned that the combination of the wearable and the actuation felt on her back made her feel as being supported and the inflation/deflation was verbally articulated by her as something "lifting me up" and then carefully "taking me down". This was quite similar to Madeline's experiences when trying the big shapes, but also different, since Madeline felt like "merging into something", instead of being lifted and taken down. Similar to Madeline's experience, Anna's experience of the smaller shapes, compared to the big shapes, was quite unpleasant and she expressed that their "pointy" qualities made her feel jittery, as they filled up with air much quicker than the big ones. At this point, we all discussed that we need to be able to control and program fine nuances and subtle inflation/deflation in both designs, aiming for careful touch qualities on other bodies. Anna suggested layering the inflatable shapes by placing the small on top of the big ones, as a way to diffuse the inflation and eliminate the pointy sensation, while keeping the experience of "being touched" in both smaller areas and bigger areas on the shoulder blades.

Finally, we all discussed that the way one wears and wraps the Breathing Wings around their body can substantially affect the intended interactive experience. Anna noted that when the shapes were inflating too much, they had a tendency to "escape" the pockets on the wearable, which she described as being slightly "creepy", especially when a latex shape escaping a pocket slightly touched the back of her arm. The shape-change materials need to be firmly in contact with the body and they should stay in the same position.

Both Anna, Madeline and Vasiliki left these sessions with many questions, ideas for new design experiments and enthusiasm for the continuing design work. The feedback we received from each other helped us to see our design work more clearly, to understand what elements of the design work were successful and where more focus was required. For the Pelvic Chair, Madeline and Anna began experimenting with new smaller shapes in different sizes to try and create a better connection with parts of the pelvic floor in ways, which were not "pokey". They also experimented with sequences of movements from the chair to help initiate a sitter to the experience of being dynamically touched by a chair. Vasiliki went away to develop new prototypes and making new Iterations. The current version of the wearable has six pockets in which latex shape change materials can be inserted and experienced simultaneously. This version can be worn inside out, depending on whether the bigger, or the smaller latex shapes will be in touch with the wearer's back. This 
decision was made for enabling a range of touch experiences, thus aiming for openness, accounting for multiple bodies and wished experiences of shape-change actuation on this bodily area, emerging from sessions of inviting others to experience the Breathing Wings.

\subsection{Scenarios to Illustrate the Intended Experience of the Pelvic Chair and Breathing Wings for Future Users}

We have presented "becoming sensitised", "establishing a red thread", "sketching with the body and materials", "sketching with others" as phases of the soma design process, which draw strongly on autobiographical and first-person perspectives. To help the reader understand the process as fully and richly as possible we have shared many first-person experiences of our design processes to illustrate how they unfold throughout the design process. At the time of writing, we are still in the midst of our design process. We continue to invite others within our design lab to sketch with us. As in every design process, the development of the prototypes has continued with further iterations, material explorations, and first-person experiential sessions. Below, we provide a scenario of the intended future experience for each prototype to help bring these designs to life for the reader.

4.5.1 Pelvic Chair: First-Person Scenario of Use and Interaction. I sit down on the Pelvic Chair, its shape makes me open up my legs and rest my pelvic floor directly on the seat. A slow inflation softly touches on the inside of my thighs and I observe how it separates my legs a little bit more, I push back gently and the inflation stops, I release pressure and the movement starts again...I start thinking what is a pleasant position for me? It becomes playful. My attention is led to another larger movement behind me, a slow inflation embracing my bottom makes my pelvis respond by tilting forward and the connection to my pelvic floor makes it rest even more on the shape of the seat. Slowly a new movement is initiated under my sitting area, in the beginning, it is hard to discern if the movement comes from within me or if it is the seat, soon it becomes a co-created movement where an inflation under my whole sitting area lifts me up, pushes and leads my pelvic floor upwards, followed by a release where my pelvic floor follows the movement and let's go into relaxation. After a while, a soft smaller inflation starts to push the left side of my pelvic floor up, my attention follows the movement, while it lets the air out again. This is repeated playing with the volume of air and the temporality of the movement, my pelvic floor responds to the movement. I choose to end my session here today, this is tiring in a way I am not used to. I am left with an increased awareness of my whole pelvic area, but the left side stands out. I find myself consciously trying to let go of the tension in the whole pelvic floor area, while doing other things, it is so easy to tense.

4.5.2 Breathing Wings: First-Person Scenario of Use and Interaction. I pick up the Breathing Wings wearable, which is resting on my reading sofa. I place it on my back and shoulders. I make sure the two "wings" (pockets where the shape-changing shapes are inserted) are touching my two shoulder blades and then I slowly start wrapping the loose fabric stripes (left and right) around my torso and waist. It takes time, but I do not mind. The process of strapping it on my body helps me to be initiated in the experience of interacting with the Breathing Wings. This process is like a ritual that prepares me for the experience that is to come. I slowly reach the end. Now it is firmly wrapped around my torso. It feels nice. I sit on the sofa and the wings attached to my back start breathing. I feel their subtle inflation and deflation, touching my skin. At times, pushing me subtly or touching me softly (feels almost like a gentle stroke on my back) on the outline of my shoulder blade bones. Firstly, I observe and surrender to the experience. Without really noticing it, I feel my back responding to their movements, gently, and subtly. I start tilting my back very slowly towards one side. I wish for a mirrored suggestive movement. Am I leading or following the movements of my wings? Or both? By inflating and deflating they are suggesting movements and I can decide 
whether I want to follow or not, or I can suggest a new movement, and the wings decide whether to follow, or not. Through this experience, I get an increased awareness of my back and I slowly start imagining and almost "seeing" the outline of my shoulder blades and the anatomy of this area on my body: the muscle structure, the bones, the soft, and hard tissue.

\section{DISCUSSION}

These thick and detailed descriptions of our soma design processes are shared with a number of goals in mind: (1) to show how first-person methods unfold when designing with bodies; (2) to highlight the value and relevance of first-person methods for soma design; (3) to illustrate how design judgements are made through using one's first-person somatic experiences from the perspective of a designer. In what follows, we discuss how we conceive of rigour and validity within the soma design process, and the role that first-person methods have in achieving this.

\subsection{The Value of First-Person Perspectives for Soma Design}

Soma design methods strongly rely on first-person perspectives, as previously articulated in [37], for example, and as pointed out in the call for this special issue. Our design processes, presented here confirm this and also show us that a first-person perspective is fundamental for soma design. In [15], the authors stress the importance of showing the detail in the design process, and how firstperson, autobiographical experiences led to certain design decisions. This is what we have tried to achieve in this article, by providing a rich and evocative account of our design processes so far, and the ways in which we have used our somas to explore materials and develop prototypes. We showed in detail, how we have started from our first-person reflections and articulations of somatic experiences, as a way of opening up a design space. But we also showed how first-person experiences continued to be focal during the next phases of both design processes, offering a ground for critique, and evaluation, through the design and experiential qualities extracted from first-person experiences that contributed to "following a red thread" throughout design processes. So, we hope, perhaps for the first time, to have shared a detailed description of how we used first-person methods within the soma design process such that the process itself can be examined and scrutinised by our peers.

Soma Design belongs to a research through design tradition, where rigour does not build from strictly following a method, which may be the case in more traditional HCI research [71]. Instead, rigour is grounded in the experience of the designers and is commonly referred to as design judgement [53], reflection in action [58], or search for appropriateness [13]. The design judgements (as we choose to call them) in our case are made from first-person experiences of sketching with the body, exploring materials, and step by step shaping of a prototype. Rigour in this process is shown by opening up and sharing the detailed description of the design process with design decisions, so it can be critiqued and examined by others. The difference in soma design, when compared with most other design processes, lies in making these judgements directly with one's body, rather than just imagining from previous experience how it might feel. As a soma designer, you both build up a more traditional design repertoire of knowing from previous experience what may and may not work, but you also build up a somaestethic design repertoire that resides in the soma [53]. We argue that this close attention to how our somas have shaped our design work is essential for showing the rigour of soma design, and of first-person perspectives within interaction design, more broadly. In soma design, the "red thread", comprising of a collection of experiential qualities, could be understood as a type of design guidelines that are set initially and which the designer uses as a way of reflection and critique along the way, but still allows the designer to open up design explorations. Staying close to the qualities set by the designer, and coming back to them, to 
experience, test, feel, and reflect with one's soma (including body, mind, emotions and subjective understanding and values) provides rigour to the process.

Looking at how the "red thread" of the design and experiential qualities evolved in the case of developing the Breathing Wings, Vasiliki initially used her body as a starting point for exploring what types of somatic experiences she would design for, that would be evocative for others. By becoming sensitised to the area of the shoulder blades and upper back, as a way to zoom in to the bodily area being in focus, she engaged with estrangement and defamiliarisation methods (wearing a pair of wings and reflecting on this experience) to open up the design space. Slowly, the design and experiential qualities of "being held", "feeling embraced", and "being taken care of" started to emerge, and become more concrete along the way, as somatic experiences that could be "world-changing" for others, as they were for Vasiliki. Working with her body, shape-change materials, and textiles (among other materials) she slowly started giving form and shape to these somatic experiences through touch qualities felt on the shoulder blades and upper back, evoked through shape-change latex shapes. Staying close to the "red thread" of the qualities is not an easy process, but needs reflection, critique, and coming back to experience in the first-person how materials can be shaped to evoke such qualities in interaction. When Vasiliki invited Madeline and Anna to experience the Breathing Wings prototype she observed how some of the qualities were communicated through the prototype, while others failed to be communicated. Both Madeline and Anna shared how the combination of the wearable's form factors and the touch qualities evoked through the bigger shapes gave them experiences of being embraced (articulated in different ways). But at the same time, the quality of "being held", for example, failed to be communicated to Madeline, while it did to Anna. And, the smaller shapes failed to communicate the intended experiential qualities, for various reasons. The process of engaging her body (Vasiliki's) and the other bodies (Madeline's and Anna's) in experiencing the prototype helped her to come back to these qualities, and stay close to them. It also helped her to develop the intended interactive experience further, and ultimately design for touch qualities that would create a space for others to potentially have "world making" experiences dynamically shaped between their somas, the shape-change materials, and the wearable.

Connected to the topic of value of first-person perspective in soma design, is the impact and scope of the outcome it produces. A common criticism of first-person methods, in general, is that they tend to become too narcissistic and less connected to what seems to be more urgent questions in our society right now. Here, we can only reason around the value of first-person perspective in soma design. Firstly, soma design in itself has a strong political agenda [37, 39]. It questions the inherent Cartesian division in our society and how this makes designs that push us to live in a certain way, like the underlying conforming mainstream approach of representationalism designing for e.g., screen-based solutions resulting in cognitive overload and sedentary lifestyles. Soma design does this in a way that does not propose a band aid when the damage is already done, like designing a mobile application to encourage movement when the way our society has conformed in setting the norms for how to work and live is the underlying problem. Instead, soma design turns to the soma of the individual and the intelligence that resides there, inviting designers to understand and transfer these first hand experiences into designs that promote living better lives and open up for a plurality of bodies and experiences [39]. Secondly, by its approach of turning to the soma, it explores, captures, and transfers some fundamental qualities of somaesthetic appreciation in the prototypes, which, in stressful and pressing times, can help us cope with the uncontrollable situation we are in. In the Breathing Wings, this is shown by the design of intimate touch of the back. Intimate touch is known to be important for our emotional wellbeing [23, 31], where the back plays a specific role in pleasant touch [45]. The Pelvic Chair could potentially help a large number of people suffering from weak pelvic floor musculature having problems with 
incontinence, involuntary flatulence, and prolapse causing social anxiety and depression [29]. The soma approach with its first-person perspective questions and provides alternatives to underlying values, norms, and structures in our society.

\subsection{Soma Design as Dynamic and Open for Many Bodies}

As we have discussed, in the previous section, first-person methods are really the backbone of soma design. The soma designer uses their soma, and specific first-person approaches to identify design qualities, which might be "world changing", to build prototypes, and to examine and critique ongoing design work. And, this central use of the soma as a starting point and continual reference point for the soma design process, is often viewed as a limitation. Kristina Höök and co-authors discuss this elsewhere [38], unpacking how the first-person perspective colours the designer's choices, and in some sense also blinds the designer to the ways in which each designer's own lived experiences may be different to those with other bodies, short, tall, fat, thin, black, and white. And, elsewhere, it has been articulated that design students, when learning about the soma design approach, wonder if a piece of design begins with the soma of the designer, then how can knowledge developed through this process be considered valid, and the resulting designs generalisable or even transferable to other somas [66]. So, let us try to unpick this limitation a little, and identify where the knowledge is in soma design, and how this knowledge gets produced in ways, which make it meaningful.

In the Webster dictionary, validity is broadly defined as "the state or quality of being wellgrounded, sound, or correct" [1]. Such a definition seems like a reasonable foundation for research through design work, as well as qualitative, or quantitative approaches within interaction design. In quantitative research, validity is construed as the extent to which the measure(s) in use are accurate at measuring the phenomena of interest, and reliability refers to the stability of findings when applied to a wider population. But, this ability to generalise results to a wider population is not normally the goal of qualitative research, and in particular not within research through design work $[36,49,56,74]$. This is also not the claim made by autobiographical design research and autoethnographies in interaction design. Carman Neustaedter [54] is quite specific in his own writing around autobiographical design research, that it should not be seen as generalisable, but instead a way of understanding pertinent issues related to emerging technology, and constructing research questions. Our work is situated within the design, which is characterised by dealing with shifting environments, where there are not any fixed contexts to generalise to. Instead, generativity, and extensions of knowledge are discussed [25, 36, 71, 74]. To make something become generative or a knowledge extension, you have to reflect upon the design and design process and abstract knowledge. This knowledge can take many forms, for example, design programs [56], experiential qualities [49], strong concepts [36], annotated portfolios [25]. But, what makes soma design different from other autobiographical work is perhaps its intent. It is often the intent of the designer that the resulting soma design be used and useful to other somas. In our work, we both extract experiential qualities for other designers to build from, and apply them in our designed prototypes in order to abstract the designed interaction from our own unique experiences to become used and useful to others in many ways. This can be understood as being generative in the actual experience rather than to be generalisable.

To help us think about how it might transpire that soma designs deeply intertwined with our own somas might be generative for other somas we turn to Karen Barad's writing on new materialism, and in particular her thoughts on agential realism [5]. As has been introduced elsewhere recently within HCI [11, 24], Karen Barad [5], and a number of others [8, 30], take the perspective that materials, bodies, objects, artefacts and matter all have agency, and play an active role in 
the construction of meaning, culture and knowledge. Such a theoretical turn opposes social constructivist views of the world, where matter/artefacts/objects/things are dead, and only made to matter or come into significance through discourse and culture, i.e., that things themselves only have value when language and culture are applied to them. Instead, within new materialism, matter does not exist as a thing, but rather matter is a "doing". "Mattering" signifies the idea that what matters is dynamic phenomena produced through intra-actions between materials, bodies, objects, and artefacts. The use of intra-action here is of significance, and reflects the new materialist worldview that there are no inherent boundaries between objects (as is suggested by the term interaction). What makes up the boundary of something only becomes known through its intra-actions with other things.

If we bring this lens to our own work, and that of soma design, then we start to think not that the soma acts on the soma designed artefact, or that the soma designed artefact acts on the soma, but instead, the soma and soma designed artefact intra-act together to produce the phenomena that (if successful) creates new meanings, new practices, new knowledge, and potentially new worlds. Karen Barad is a theoretical physicist and many of examples are drawn from Bohr's radical work in quantum physics. She writes extensively about apparatus and the role the human plays in the production of measurements produced by apparatus in the lab. In [4], she describes apparatus as:

"the material conditions of possibility and impossibilities of mattering; they enact what matters and what is excluded from mattering"

We could think of the soma designed artefacts that we make as a kind of apparatus-a material configuration, that dynamically re-configures the world, through the intra-actions, and entanglements that are made possible with it. A soma designed artefact creates the conditions (the boundaries, and properties of entities) by which matterings of certain phenomena may arise, and others not. To achieve this within a soma designed aretfact (or apparatus if you will) we must pay great attention to design in ways which are dynamic, which create a certain bounded openness. We do this since the soma is dynamic and open, where new experiences create new opportunities, which may in turn create new ways of being and living [37]. This dynamism in soma design starts with the identifying design qualities grounded in first-person somatic explorations. We find this to be somewhat akin to hunting for the new phenomena that could be "world making" [5], as we search for material-body entanglements, which can open up new possibilities, new experiences, new worlds for our somas, and to become generative [64] This is articulated, for example, by Madeline and Anna as they iteratively return to and discuss, which Feldenkrais exercises gave them a totally new perspective or experience on their somas-the resulting focus on relaxational power, unitedness, differentiation, and connectedness, were for Madeline and Anna "world making". Along the way they discarded somatic experiences that did not maintain interest, focusing instead in those that gave new aesthetic somatic experiences every time that they were experienced. This perspective on Soma Design suggests that meaning is constantly being made in the intra-action between the object (the matter, in this case the designed artefact) and the soma. The soma is reconfigured through its entanglements with the soma design artefact. You cannot look at a soma design and know what it is about, and how it may be meaningful, you have to experience it, to intra-act with it, in order to know. What is mattered in the moment of use is shaped in the moment between the soma design artefact and the soma itself. What we are trying to articulate, is that a specific soma, in a specific time and place, intra-acting with a specific design is where a particular mattering happens, is articulated or understood.

We can see this mattering in some of the thick descriptions shared of our soma design process. For example, where Madeline establishes through intra-actions with Feldenkrais exercises how her pelvic floor muscles work, and where they do not work. In contrast to the surgeons' description of 
her body, Madeline is able to produce a new meaning about her body, her soma is remade. Taking the Breathing Wings as another example, this artefact became "mattering" for Vasiliki as it foregrounded new and evocative experiences at the intersection between her body and the wearable. The actuation felt on the skin in the form of inflation/deflation made her experience the touch of the shape-change as a leakage towards her flesh, feeling almost like it spilled towards the inside of her shoulder blades-reaching the muscles and bones. This "world making" experience that she designed, made her not only feel, but also almost "see" the anatomy of her back through her intra-actions with the prototype. Both Madeline's and Vasiliki's experiences articulated through the concept of intra-actions are not so dissimilar from the reciprocal shaping experienced by Audrey Desjardin and Ron Wakkary, where they observe that as the project changes over time, so do they-the designers-change as well [16].

We intend that our soma design should be used and be generative in creating experiences to other somas than our own, but we do not pretend that for every soma sitting on the Pelvic Chair, or wearing the Breathing Wings, that there are generalisable experiences, nor even transferable experiences. We are aiming for something else. The mattering that emerges will be a dynamic entanglement between the soma design, and the soma. The designed soma artefact should offer an open, yet bounded experience. It should not prescribe one experience, nor infinite experiences. In this sense, an approach to understanding the validity of soma design is close to those argued for within feminist research, to account for a plurality of bodies and experiences [39], to be applicable to many [14].

\subsection{Doing "World Making” Design}

Karen Barad's [5] writings on agential realism and how apparatus and humans become part of the world's ongoing reconfiguring is what we refer to as world making. Following her thoughts, we cannot design prototypes for creating a certain knowledge, but we are ourselves part of the becoming in these intra-actions. A focus on "world making" makes for a very ambitious design program. And, of course "world making" experiences can vary between people (and we see this with Madeline and Anna, where Anna is very inspired by the experience of relaxation, which is new and evocative to her, but this is less meaningful to Madeline)-this naturally means, that sometimes the experiences created fail to be "world making" for all somas. That can be seen as a limitation of this approach, but the intention is rather to open up for a generation of different experiences within boundaries, depending on the material (including bodies) you provide. To design for intraaction within boundaries, there are things that we can do to create a soma design that has meaning for somas beyond our own:

- Ongoing Somatic Engagement with Experiential Qualities: The selection of the experiential qualities that ground the design is crucial, to ensure that these offer continuing potential for becoming. In our own processes, we have found it fruitful to return multiple times to the somatic experiences and qualities throughout a design process to ensure that they remain experienced in a meaningful, aesthetic, and evocative way. Kristina Höök talks about this as Soma Slowstorming [37], the act of coming back to a somatic experience multiple times in order to understand the aims of the design. By coming back to somatic experiences-through first-person methods-we find that we are able to distinguish between those that have a novelty effect, and those which are genuinely somaesthetic. In this article, we have contributed to this literature, by providing our own thick descriptions of our "soma slowstorming activities", with a particular focus on how we arrive at, return to, and critique experiential design qualities as an ongoing part of the design process. 
- Inviting Other People In: We invite other people to try and experience design work as it develops-from low fidelity onwards. This becomes part of the process of understanding whether the qualities we have given a design are "world making" for others. As we work with others, we look for the potential in our apparatus to give rise to the phenomena people might come back to over time. We are not aiming to persuade others that our own experienced matterings exist, but to develop together a collection of first-person perspectives and matterings. At the same time, as the reader may notice, we have not invited just anybody into the design process, but rather, someone who has a knowledge of the design process we are following, and who has been cultivating somatic design judgement. For us, this choice was grounded in getting relevant expertise feedback on designs that were still in the making, as well as a matter of comfort-doing soma design and digging deep into first-person experiences and sharing such experiences with others is a design process, which, at times can be hard to separate from yourself, from vulnerabilities, and emotions that emerge when engaging with the body [3].

- Surrendering to the Process, and Cultivating Design Judgement: Kristina Höök speaks about the skill involved in attending to the soma elsewhere [37]. We wish to extend on this by suggesting that the soma designer needs to cultivate judgement as to what somatic experiences are "world making", aesthetically interesting enough to capture the interest and attention of many somas. Soma design judgement needs to be developed over time, just like any other form of design judgement or critique. Knowing what qualities may lead to something "world changing", what may be open enough, while creating a bounded experience is something that we learn over time and through multiple experiences. In the rich descriptions provided of our ongoing work on the Breathing Wings and Pelvic Chair, we are not only continuing to cultivate soma design judgement in general, but cultivating design judgement with parts of the body that we do not usually use to sense and critique design. To think through the pelvis or back is strange. It is tiring to sense deeply with parts of the body that we do not normally sense with often, and for these reasons, we found prototyping sessions are often short, as we try different materials on the body, different temporal interactions, and develop our thinking and work. Much as Jeffrey Bardzell highlights in his writing around interaction criticism [6], we find that as we sense with our somas, and use parts of our somas that we do not often sense with, that our abilities to perceive and judge with these parts increases. The whole soma design process is one which is slow, and requires time, energy, and patience as we cultivate our somatic judgements, and ability to perceive, and our imaginings of what is possible.

\section{CONCLUSION}

We put two ongoing soma design projects in conversation with one another to articulate the key moments in a soma design process. Our processes show us that a first-person perspective is fundamental for soma design. We cannot begin to design for connections between sensations, feelings, emotions, subjective understandings, and values only through the experiences of others, we must use our own somas to experience and make design judgements. We have highlighted how "experiential design qualities" are derived from ongoing, iterative somatic work, and that these design qualities serve as a one knot in a red thread that flows throughout the entire design process. We have also illustrated how working with materials in combination with our somas serves as another knot in this red thread, and that in combination, these anchors help to ensure rigour in our work.

The centrality of first-person perspectives is at the root of many criticisms of soma designnamely, how can the interaction designs resulting through this extremely first-person-centric 
process be of relevance or inclusive to other somas? Using Karen Barad's concept of intra-action and mattering, we have argued that soma design can be "world making". The phenomena-the thing that comes to matter-that occurs between the soma and the artefact will be unique to the particular soma, the particular time and place of intra-action. No two experiences on the Pelvic Chair, or wearing the Breathing Wings will ever be the same. Thus, instead of trying to replicate experiences across people, the validity of soma design is born out of its ability to accommodate different somas. To have the potential to make-worlds for different somas. The focus should be on trying to create an artefact that offers the conditions for new experiences and new knowledge to occur and reoccur through use. The soma designer must place their focus on identifying and staying true to experiential design qualities which can resonate, and matter to all kinds of somas.

\section{ACKNOWLEDGMENTS}

We thank our colleagues at the KTH Royal Institute of Technology for providing an inspiring and accepting place for going on this research journey, for not minding as we giggled together pumping balloons under one another, and generally doing strange things with materials and our bodies. We thank our students at KTH for showing us that this article was needed.

\section{REFERENCES}

[1] Definition of VALIDITY. Retrieved from https://www.merriam-webster.com/dictionary/validity.

[2] Teresa Almeida, Rob Comber, Gavin Wood, Dean Saraf, and Madeline Balaam. 2016. On looking at the vagina through labella. In Proceedings of the 2016 CHI Conference on Human Factors in Computing Systems.

[3] Madeline Balaam, Rob Comber, Rachel E. Clarke, Charles Windlin, Anna Ståhl, Kristina Höök, and Geraldine Fitzpatrick. 2019. Emotion work in experience-centered design. In Proceedings of the 2019 CHI Conference on Human Factors in Computing Systems (CHI'19). Association for Computing Machinery, New York, NY, 1-12. DOI: https: //doi.org/10.1145/3290605.3300832

[4] Karen Barad. 2003. Posthumanist performativity: Toward an understanding of how matter comes to matter. Signs: Journal of Women in Culture and Society 28, 3 (2003), 801-831. DOI : https://doi.org/10.1086/345321

[5] Karen Barad. 2007. Meeting the Universe Halfway-Quantum Physics and the Entanglement of Matter and Meaning. Duke University Press. Retrieved fom https://www.dukeupress.edu/meeting-the-universe-halfway.

[6] Jeffrey Bardzell. 2011. Interaction criticism: An introduction to the practice. Interacting with Computers 23, 6 (Nov. 2011), 604-621. DOI : https://doi.org/10.1016/j.intcom.2011.07.001 Publisher: Oxford Academic.

[7] Jeffrey Bardzell, Shaowen Bardzell, Peter Dalsgaard, Shad Gross, and Kim Halskov. 2016. Documenting the research through design process. In Proceedings of the 2016 ACM Conference on Designing Interactive Systems (DIS'16). Association for Computing Machinery, New York, NY, 96-107. DOI : https://doi.org/10.1145/2901790.2901859

[8] Jane Bennett. 2010. Vibrant Matter: A Political Ecology of Things. Duke University Press.

[9] Francesco Bigoni and Cumhur Erkut. 2020. DogDog: Soma-based interface design for an improvising musician. In Proceedings of the 7th International Conference on Movement and Computing (MOCO'20). Association for Computing Machinery, New York, NY, 1-4. DOI : https://doi.org/10.1145/3401956.3404242

[10] Marta E. Cecchinato, Anna L. Cox, and Jon Bird. 2017. Always on(line)? User experience of smartwatches and their role within multi-device ecologies. In Proceedings of the 2017 CHI Conference on Human Factors in Computing Systems (CHI'17). Association for Computing Machinery, New York, NY, 3557-3568. DOI : https://doi.org/10.1145/3025453. 3025538

[11] Rob Comber, Airi Lampinen, and Jesse Haapoja. 2019. Towards post-interaction computing: Addressing immediacy, (un)intentionality, instability and interaction effects. In Proceedings of the Halfway to the Future Symposium 2019. ACM, 1-8. DOI : https://doi.org/10.1145/3363384.3363477

[12] Karin S. Coyne, Chris C. Sexton, Christine L. Thompson, Ian Milsom, Debra Irwin, Zoe S. Kopp, Christopher R. Chapple, Steven Kaplan, Andrea Tubaro, Lalitha P. Aiyer, and Alan J. Wein. 2009. The prevalence of lower urinary tract symptoms (LUTS) in the USA, the UK and Sweden: Results from the epidemiology of LUTS (EpiLUTS) study. BJU International 104, 3 (Aug. 2009), 352-360. DOI : https://doi.org/10.1111/j.1464-410X.2009.08427.x

[13] Nigel Cross. 2006. Designerly Ways of Knowing. Springer-Verlag, Berlin. DOI : https://doi.org/10.1007/1-84628-301-9

[14] Elise J. Dallimore. 2000. A feminist response to issues of validity in research. Women's Studies in Communication 23, 2 (April 2000), 157-181. DOI : https://doi.org/10.1080/07491409.2000.10162567 
[15] Audrey Desjardins and Aubree Ball. 2018. Revealing tensions in autobiographical design in HCI. In Proceedings of the 2018 Designing Interactive Systems Conference (DIS'18). Association for Computing Machinery, New York, NY, 753-764. DOI : https://doi.org/10.1145/3196709.3196781

[16] Audrey Desjardins and Ron Wakkary. 2016. Living in a prototype: A reconfigured space. In Proceedings of the 2016 CHI Conference on Human Factors in Computing Systems (CHI'16). Association for Computing Machinery, New York, NY, 5274-5285. DOI : https://doi.org/10.1145/2858036.2858261

[17] Audrey Desjardins, Ron Wakkary, Will Odom, Henry Lin, and Markus Lorenz Schilling. 2017. Exploring DIY tutorials as a way to disseminate research through design. Interactions 24, 4 (June 2017), 78-82. DOI : https://doi.org/10.1145/ 3098319

[18] Laura Devendorf, Kristina Andersen, and Aisling Kelliher. 2020. The fundamental uncertainties of mothering: Finding ways to honor endurance, struggle, and contradiction. ACM Transactions on Computer-Human Interaction 27, 4 (Sept. 2020), 1-24. DOI : https://doi.org/10.1145/3397177

[19] Laura Devendorf, Kristina Andersen, and Aisling Kelliher. 2020. Making design memoirs: Understanding and honoring difficult experiences. In Proceedings of the 2020 CHI Conference on Human Factors in Computing Systems (CHI'20). Association for Computing Machinery, New York, NY, 1-12. DOI : https://doi.org/10.1145/3313831.3376345

[20] Carolyn Ellis and Arthur P. Bochner. 1999. Bringing emotion and personal narrative into medical social science. Health 3, 2 (1999), 229-237. DOI : https://doi.org/10.1177/136345939900300206

[21] Sarah Fdili Alaoui, Thecla Schiphorst, Shannon Cuykendall, Kristin Carlson, Karen Studd, and Karen Bradley. 2015. Strategies for embodied design: The value and challenges of observing movement. In Proceedings of the 2015 ACM SIGCHI Conference on Creativity and Cognition (C\& C'15). Association for Computing Machinery, New York, NY, 121-130. DOI : https://doi.org/10.1145/2757226.2757238

[22] Moshe Feldenkrais. 1972. Awareness Through Movement. Vol. 1977. Harper and Row, New York.

[23] Tiffany Field. Touch, Second Edition. 2014. The MIT Press. Retrieved from https://mitpress.mit.edu/books/touch.

[24] Christopher Frauenberger. 2020. Entanglement HCI the next wave? ACM Transactions on Computer-Human Interaction 27, 1 (Jan. 2020), 1-27. DOI : https://doi.org/10.1145/3364998

[25] Bill Gaver and John Bowers. 2012. Annotated portfolios. Interactions 19, 4 (July 2012), 40-49. DOI : https://doi.org/10. 1145/2212877.2212889

[26] B. Gaver, T. Dunne, and E Pacenti. 1999. Cultural probes. Interactions 6, 1 (1999), 21-29.

[27] William W. Gaver. 2006. The video window: My life with a ludic system. Personal and Ubiquitous Computing 10, 2 (April 2006), 60-65. DOI : https://doi.org/10.1007/s00779-005-0002-2

[28] Clifford Geertz. 1973. Thick description: Toward an interpretive theory of culture. Turning Points in Qualitative Research: Tying Knots in a Handkerchief 3 (1973), 143-168. AltaMira Press, Walnut Creek, CA.

[29] Nils Hansson Vikström, Elisabet Wasteson, Anna Lindam, and Eva Samuelsson. 2021. Anxiety and depression in women with urinary incontinence using E-health. International Urogynecology fournal 32, 1 (Jan. 2021), 103-109. DOI : https://doi.org/10.1007/s00192-020-04227-2

[30] Donna Haraway. 2016. Staying with the Trouble. Duke University Press.

[31] Matthew J. Hertenstein. 2002. Touch: Its communicative functions in infancy. Human Development 45, 2 (2002), $70-94$. DOI : https://doi.org/10.1159/000048154

[32] Yasamin Heshmat, Carman Neustaedter, and Brendan DeBrincat. 2017. The autobiographical design and long term usage of an always-on video recording system for the home. In Proceedings of the 2017 Conference on Designing Interactive Systems (DIS'17). Association for Computing Machinery, New York, NY, 675-687. DOI : https://doi.org/10.1145/ 3064663.3064759

[33] Sarah Homewood, Amanda Karlsson, and Anna Vallgårda. 2020. Removal as a method: A fourth wave HCI approach to understanding the experience of self-tracking. In Proceedings of the 2020 ACM Designing Interactive Systems Conference (DIS'20). Association for Computing Machinery, New York, NY, 1779-1791. DOI : https://doi.org/10.1145/3357236. 3395425

[34] Kristina Höök, Caroline Hummels, Katherine Isbister, Patrizia Marti, Elena Márquez Segura, Martin Jonsson, Florian "Floyd" Mueller, Pedro A.N. Sanches, Thecla Schiphorst, Anna Ståhl, Dag Svanaes, Ambra Trotto, Marianne Graves Petersen, and Youn-kyung Lim. 2017. Soma-based design theory. In Proceedings of the 2017 CHI Conference Extended Abstracts on Human Factors in Computing Systems (CHI EA'17). Association for Computing Machinery, New York, NY, 550-557. DOI : https://doi.org/10.1145/3027063.3027082

[35] Kristina Höök, Martin Jonsson, Anna Ståhl, Jakob Tholander, Toni Robertson, Patrizia Marti, Dag Svanaes, Marianne Graves Petersen, Jodi Forlizzi, Thecla Schiphorst, Katherine Isbister, Caroline Hummels, Sietske Klooster, Lian Loke, and George Poonkhin Khut. 2016. Move to be moved. In Proceedings of the 2016 CHI Conference Extended Abstracts on Human Factors in Computing Systems (CHI EA'16). Association for Computing Machinery, New York, NY, 3301-3308. DOI : https://doi.org/10.1145/2851581.2856470 
[36] Kristina Höök and Jonas Löwgren. 2012. Strong concepts. ACM Transactions on Computer-Human Interaction 19, 3 (2012), 1-18. DOI : https://doi.org/10.1145/2362364.2362371

[37] Kristina Höök. 2019. Designing with the Body. MIT Press. Retrieved from https://doi.org/10.7551/mitpress/11481.001. 0001.

[38] Kristina Höök, Baptiste Caramiaux, Cumhur Erkut, Jodi Forlizzi, Nassrin Hajinejad, Michael Haller, Caroline Hummels, Katherine Isbister, Martin Jonsson, George Khut, Lian Loke, Danielle Lottridge, Patrizia Marti, Edward Melcer, Florian Müller, Marianne Petersen, Thecla Schiphorst, Elena Segura, Anna Stlaahl, Dag Svanæs, Jakob Tholander, and Helena Tobiasson. 2018. Embracing first-person perspectives in soma-based design. Informatics 5, 1 (2018), 8. DOI : https://doi.org/10.3390/informatics5010008

[39] Kristina Höök, Sara Eriksson, Marie Louise Juul Søndergaard, Marianela Ciolfi Felice, Nadia Campo Woytuk, Ozgun Kilic Afsar, Vasiliki Tsaknaki, and Anna Ståhl. 2019. Soma design and politics of the body. In Proceedings of the Halfway to the Future Symposium 2019 (HTTF 2019). Association for Computing Machinery, New York, NY, 1-8. DOI : https: //doi.org/10.1145/3363384.3363385

[40] Debra E. Irwin, Ian Milsom, Steinar Hunskaar, Kate Reilly, Zoe Kopp, Sender Herschorn, Karin Coyne, Con Kelleher, Christian Hampel, Walter Artibani, and Paul Abrams. 2006. Population-based survey of urinary incontinence, overactive bladder, and other lower urinary tract symptoms in five countries: Results of the EPIC study. European Urology 50, 6 (Dec. 2006), 1306-1315. DOI : https://doi.org/10.1016/j.eururo.2006.09.019

[41] William James. 1905. The experience of activity. Psychological Review 12, 1 (1905), 1.

[42] Hsia-Tzu Kao, Mark Hayter, Sharron Hinchliff, Chuan-Hsiu Tsai, and Min-Tao Hsu. 2015. Experience of pelvic floor muscle exercises among women in Taiwan: A qualitative study of improvement in urinary incontinence and sexuality. Journal of Clinical Nursing 24, 13-14 (2015), 1985-1994. DOI : https://doi.org/10.1111/jocn.12783

[43] George Poonkhin Khut. 2006. Development and Evaluation of Participant-Centred Biofeedback Artworks. Ph.D. Dissertation. Western Sydney University, Penrith, NSW, Australia.

[44] Wonjun Lee, Youn-kyung Lim, and Richard Shusterman. 2014. Practicing somaesthetics: Exploring its impact on interactive product design ideation. In Proceedings of the 2014 Conference on Designing Interactive Systems (DIS'14). Association for Computing Machinery, New York, NY, 1055-1064. DOI : https://doi.org/10.1145/2598510.2598561

[45] Jaquette Liljencrantz and Håkan Olausson. 2014. Tactile C fibers and their contributions to pleasant sensations and to tactile allodynia. Frontiers in Behavioral Neuroscience 8, 37 (2014), 1-6. DOI : https://doi.org/10.3389/fnbeh.2014.00037

[46] Lian Loke and George Poonkhin Khut. 2014. Intimate aesthetics and facilitated interaction. In Interactive Experience in the Digital Age: Evaluating New Art Practice. Linda Candy and Sam Ferguson (Eds.), Springer, Cham, 91-108. DOI : https: //doi.org/10.1007/978-3-319-04510-8_7

[47] Lian Loke, George Poonkhin Khut, and A. Baki Kocaballi. 2012. Bodily experience and imagination: Designing ritual interactions for participatory live-art contexts. In Proceedings of the Designing Interactive Systems Conference (DIS'12). Association for Computing Machinery, New York, NY, 779-788. DOI : https://doi.org/10.1145/2317956.2318073

[48] Lian Loke and Toni Robertson. 2007. Making strange with the falling body in interactive technology design. In Proceedings of the 3rd European Conference on Design and Semantics of Form and Movement. 20.

[49] Jonas Löwgren. 2007. Pliability as an experiential quality: Exploring the aesthetics of interaction design. Artifact 1, 2 (2007), 85-95. DOI : https://doi.org/10.1080/17493460600976165

[50] Andrés Lucero. 2018. Living without a mobile phone: An autoethnography. In Proceedings of the 2018 Designing Interactive Systems Conference (DIS'18). Association for Computing Machinery, New York, NY, 765-776. DOI : https: //doi.org/10.1145/3196709.3196731

[51] Andrés Lucero, Audrey Desjardins, Carman Neustaedter, Kristina Höök, Marc Hassenzahl, and Marta E. Cecchinato. 2019. A sample of one: First-person research methods in HCI. In Proceedings of the Companion Publication of the 2019 on Designing Interactive Systems Conference 2019 Companion (DIS'19 Companion). Association for Computing Machinery, New York, NY, 385-388. DOI : https://doi.org/10.1145/3301019.3319996

[52] Svetlana Mironcika, Annika Hupfeld, Joep Frens, Jessica Asjes, and Stephan Wensveen. 2020. Snap-snap t-shirt: Posture awareness through playful and somaesthetic experience. In Proceedings of the 14th International Conference on Tangible, Embedded, and Embodied Interaction (TEI'20). Association for Computing Machinery, New York, NY, 799-809. DOI : https://doi.org/10.1145/3374920.3375013

[53] Harold Nelson, Stolterman, and Erik. 2012. The Design Way, Second Edition. The MIT Press. https://doi.org/10.7551/ mitpress/9188.001.0001

[54] Carman Neustaedter and Phoebe Sengers. 2012. Autobiographical design: What you can learn from designing for yourself. Interactions 19, 6 (Nov. 2012), 28-33. DOI : https://doi.org/10.1145/2377783.2377791

[55] Aisling Ann O'Kane, Yvonne Rogers, and Ann E. Blandford. 2014. Gaining empathy for non-routine mobile device use through autoethnography. In Proceedings of the SIGCHI Conference on Human Factors in Computing Systems (CHI'14). Association for Computing Machinery, New York, NY, 987-990. DOI : https://doi.org/10.1145/2556288.2557179

[56] Johan Redström. 2017. Making Design Theory. The MIT Press. DOI: https://doi.org/10.7551/mitpress/11160.001.0001 
[57] Thecla Schiphorst. 2011. Self-evidence: Applying somatic connoisseurship to experience design. In CHI'11 Extended Abstracts on Human Factors in Computing Systems. Association for Computing Machinery, New York, NY, 145-160.

[58] Donald Schön. 1983. The Reflective Practitioner : How Professionals Think in Action. Routledge. DOI : https://doi.org/10. 4324/9781315237473

[59] Maxine Sheets-Johnstone. 2011. The Primacy of Movement. John Benjamins. Retrieved from https://www.jbe-platform. com/content/books/9789027286772.

[60] Richard Shusterman. 2008. Body Consciousness: A Philosophy of Mindfulness and Somaesthetics. Cambridge Univeristy Press.

[61] Marie Louise Juul Søndergaard, Ozgun Kilic Afsar, Marianela Ciolfi Felice, Nadia Campo Woytuk, and Madeline Balaam. 2020. Designing with intimate materials and movements: Making "Menarche Bits". In Proceedings of the 2020 ACM Designing Interactive Systems Conference (DIS'20). Association for Computing Machinery, New York, NY, 587-600. DOI : https://doi.org/10.1145/3357236.3395592

[62] Anna Ståhl, Martin Jonsson, Johanna Mercurio, Anna Karlsson, Kristina Höök, and Eva-Carin Banka Johnson. 2016. The soma mat and breathing light. In Proceedings of the 2016 CHI Conference Extended Abstracts on Human Factors in Computing Systems (CHI EA'16). Association for Computing Machinery, New York, NY, 305-308. DOI : https://doi.org/ $10.1145 / 2851581.2889464$

[63] Dag Svanaes and Martin Solheim. 2016. Wag your tail and flap your ears: The kinesthetic user experience of extending your body. In Proceedings of the 2016 CHI Conference Extended Abstracts on Human Factors in Computing Systems (CHI EA'16). Association for Computing Machinery, New York, NY, 3778-3779. DOI : https://doi.org/10.1145/2851581. 2890268

[64] Marita Svane. 2014. Quantum organizational World-making through material emobided storytelling practices. In Proceedings of the Quantum Storytelling Conference. New Mexico University.

[65] Paul Tennent, Joe Marshall, Vasiliki Tsaknaki, Charles Windlin, Kristina Höök, and Miquel Alfaras. 2020. Soma design and sensory misalignment. In Proceedings of the 2020 CHI Conference on Human Factors in Computing Systems (CHI'20) Association for Computing Machinery, New York, NY, 1-12. DOI : https://doi.org/10.1145/3313831.3376812

[66] Vasiliki Tsaknaki, Madeline Balaam, Anna Ståhl, Pedro Sanches, Charles Windlin, Pavel Karpashevich, and Kristina Höök. 2019. Teaching soma design. In Proceedings of the 2019 on Designing Interactive Systems Conference (DIS'19). Association for Computing Machinery, New York, NY, 1237-1249. DOI : https://doi.org/10.1145/3322276.3322327

[67] Jayne Wallace, Kyle Montague, Trevor Duncan, Luís P. Carvalho, Nantia Koulidou, Jamie Mahoney, Kellie Morrissey, Claire Craig, Linnea Iris Groot, Shaun Lawson, Patrick Olivier, Julie Trueman, and Helen Fisher. 2020. ReFind: Design, lived experience and ongoingness in bereavement. In Proceedings of the 2020 CHI Conference on Human Factors in Computing Systems (CHI'20). Association for Computing Machinery, New York, NY, 1-12. DOI : https://doi.org/10.1145/ 3313831.3376531

[68] Jayne Wallace, Peter C. Wright, John McCarthy, David Philip Green, James Thomas, and Patrick Olivier. 2013. A designled inquiry into personhood in dementia. In Proceedings of the SIGCHI Conference on Human Factors in Computing Systems. 2617-2626. DOI : https://doi.org/10.1145/2470654.2481363

[69] Danielle Wilde, Anna Vallgårda, and Oscar Tomico. 2017. Embodied design ideation methods: Analysing the power of estrangement. In Proceedings of the 2017 CHI Conference on Human Factors in Computing Systems (CHI'17). Association for Computing Machinery, New York, NY, 5158-5170. DOI : https://doi.org/10.1145/3025453.3025873

[70] Charles Windlin, Anna Ståhl, Pedro Sanches, Vasiliki Tsaknaki, Pavel Karpashevich, Madeline Balaam, and Kristina Höök. 2019. Soma Bits-Mediating Technology to Orchestrate Bodily Experiences. Retrieved from http://urn.kb.se/ resolve?urn=urn:nbn:se:kth:diva-253818.

[71] Tracee Vetting Wolf, Jennifer A. Rode, Jeremy Sussman, and Wendy A. Kellogg. 2006. Dispelling "Design" as the black art of CHI. In Proceedings of the SIGCHI Conference on Human Factors in Computing Systems (CHI'06). Association for Computing Machinery, New York, NY, 521-530. DOI : https://doi.org/10.1145/1124772.1124853

[72] Lillian Yang and Carman Neustaedter. 2020. An autobiographical design study of a long distance relationship: When telepresence robots meet smart home tools. In Proceedings of the 2020 ACM Designing Interactive Systems Conference (DIS'20). Association for Computing Machinery, New York, NY, 129-140. DOI : https://doi.org/10.1145/3357236.3395467

[73] Xiao Zhang and Ron Wakkary. 2014. Understanding the role of designers' personal experiences in interaction design practice. In Proceedings of the 2014 Conference on Designing Interactive Systems (DIS'14). Association for Computing Machinery, New York, NY, 895-904. DOI : https://doi.org/10.1145/2598510.2598556

[74] John Zimmerman, Jodi Forlizzi, and Shelley Evenson. 2007. Research through design as a method for interaction design research in HCI. In Proceedings of the SIGCHI Conference on Human Factors in Computing Systems (CHI'07) Association for Computing Machinery, New York, NY, 493-502. DOI : https://doi.org/10.1145/1240624.1240704

Received October 2020; revised June 2021; accepted June 2021 